\title{
Breathing Artifacts of Urban BioClimatic Layers for Post-Anthropocene Urban Environment
}

\author{
Marie Davidová \\ Cluster of Excellence Integrative Computational Design and Construction for Architecture, \\ University of Stuttgart, 70174 Stuttgart, Germany; marie.davidova@intcdc.uni-stuttgart.de
}

Citation: Davidová, M. Breathing Artifacts of Urban BioClimatic Layers for Post-Anthropocene Urban Environment. Sustainability 2021, 13, 11307. https://doi.org/10.3390/ su132011307

Academic Editors: Volker Schwieger, Philip Leistner, Cordula Kropp and Werner Sobek

Received: 7 September 2021

Accepted: 9 October 2021

Published: 13 October 2021

Publisher's Note: MDPI stays neutral with regard to jurisdictional claims in published maps and institutional affiliations.

\begin{abstract}
This article seeks the qualitative synthesis of schools of thought from extreme climate regions that could support urban biodiversity and climate change adaptation through architectural design. It proposes that climate comfort and biodiversity are closely related. This article suggests a possible systemic urban metabolism within a built environment that can support a transition to post-Anthropocene, where humans and other species live together in synergy. This article exemplifies and seeks systemic relations and reflections of gathered field studies documentation of case studies of breathing walls, envelopes, and screens generating bioclimatic layers in the cultural landscape, selected for their penetrability and performance. The samples from diverse study journeys that were codesigned through vernacular cultures and the author's research by design speculations on the responsive screen 'Ray' are investigated and speculated upon through gigamapping (visual complexity mapping). This gigamapping is not to present any hard data model but to relate, inform and speculate on the investigated field that is grounded in research by design on cross-species coliving. This is approached through possible architectures and architectural and urban design parasites, transitioning towards synergetic landscapes of our envisioned colived and cocreated futures.
\end{abstract}

Keywords: post-Anthropocene; cross-species coliving; systemic design; systems-oriented design; systemic approach to architectural performance; metabolic cities; breathing walls; responsive wood; gigamapping

\section{Introduction}

This article is an extension of a working paper from the Relating Systems Thinking and Design 8 symposium, held at the Illinois Institute of Technology, Chicago [1]. It presents, explores, and speculates on the author's field studies' material collected to support her architectural and urban design research, by designing an environment responsive screen 'Ray' [2-5]. It is a 'first-person practitioner's research' [6] survey that looks into breathing walls, envelopes, and screens to inform the development of a presented prototype, the result. This research is investigated through the lens of 'Systemic Design' [7]. The main aim of this article is to conclude on the integration of the referred schools of thought into the prototype suggested by the author and to define its application in urban environment in relation to socio-environmental aspects of complex urban metabolism. It is approached from the perspective of object-oriented ontology that maintains that objects exist independently (as Kantian noumena) of human perception and are not ontologically exhausted by their relations with humans or other objects [8]. The breathing walls, envelopes, and screens are understood in this article as penetrable boundaries of 'indiscrete urban and architectural spaces' [9]. The article uses the term wall for a self-standing construction, screen for anything that is fitted into a supportive construction, and envelope for anything enveloping a self-standing construction. It is relating such relatively small elements in connection to socio-bioclimatic relations of urban environment in a speculative manner, addressing planetary boundaries [10]. In the context of post-Anthropocene, Bratton discusses these boundaries, their un/penetrability, performance, and relations, stating: 
'.... We have a good sense of the passage from the Foucauldian disciplinary biopolitics for which bodies are captured, enveloped, individuated, nominated, and enumerated into a governable interior, into the Deleuzian "society of control" for which open fields of interfaces, switches, and gateways quantify the traces and trails of partial subjects in motion as they pace through urban landscapes, wandering without tether because there is no outside to which they might escape. Now another regime appears, one that organizes its biopolitical governance through a more immediate and affective means: the sensing and codification of risk at the level of skin (a mammal's largest sensory organ, a cell's essential structural support, a planet's most exposed inventory of life). This epidermal biopolitics is based less on "seeing like a state" than upon what a governing apparatus can sense ......

... . Drawing lines upon a planet, either by the physical inscription of walls and envelopes or by the virtual geometries of massless legal borders, is essential to anthropic politics. (Think Carl Schmitt's The Nomos of the Earth), and the multiplication and confusion of these drawings by planetary-scale computational architectures puts into play jurisdictional designations and subdivisions, or the refusal of same, and points toward unfamiliar models of geopolitical design and designation.' [11].

Jagodzinski adds to this discussion:

'The bio-artists ... propose a 'skinless society'; the metaphor addresses a society where boundaries have increasingly merged in such a way that the interfaces have become porous membranes rather than barriers to the exchange of affection most often delivered through contagion-such as epidemics and infection, but also radiation. Such borders are not simply crossed or transgressed, and not even negotiated, for unquestionably skin has become increasingly vulnerable to environmental pollutants. Screen fantasies of penetration from the outside and the eruption of rage and revenge from the inside have left little doubt that skin is no longer a membrane of separation but a medium of connectivity, as well as being intensely over-coded by media bombardment ...

... 'onion-skin' notion of the self that can lead to infinite regress. If the skin is imagined to be 'outside,' containing an 'inside' within it, then peeling it away leaves yet another 'outside,' which in turn can be peeled away to get at the inside' [12].

The penetrability of boundaries is critical for cross-species urban connectivity and interaction, and climate exchange and moderation. Therefore, the penetrable boundaries are important across design, architectural, urban and landscape scales respective to the affected areas and their size.

\subsection{Broader View}

This discussion is especially important as recently, governments worldwide have been releasing strategies and programs for climate adaptations, discussing weather, biodiversity, food security, and landscape connectivity. All these issues are closely related [13-17]. However, we must also deal with the fact that the discovery and description of Earth's biodiversity is the oldest biological science, yet it is the least developed [18]. Similarly, this discussion appears around the knowledge of past craftspersonship [19]. At the same time, the design potential of architecture to modify climatic and biological environments is underestimated, and it can happen through its boundaries [20]. Furthermore, architecture can modify these environments for better or worse, no matter what the design intention was. Irwin states that fundamental changes at every level of our society and new approaches to problem-solving are needed to address twenty-first century wicked problems such as climate change, loss of biodiversity, depletion of natural resources, and the widening gap between rich and poor [21]. Again, our society addresses them for better or worse no 
matter the intention, because all our actions and artifacts are 'hyperobjective' [22]. In this context, urban metabolism and 'bioregioning' [23] are critical to possible transitions towards adaptations that could lead towards a 'better' future, if we better analyse and adapt our environment with the consideration of a larger complexity, whilst adapting through 'leverage points' [24]. Ken Friedman described design as a continuum, where there is at one end simplicity in the form of artifacts, processes, products, and services; at the other hand, there is complexity, often in complex adaptive systems, networks, and processes that straddle the traditional boundaries of many organizations [25]. This article unveils the complex adaptive systems of cities and regions' metabolism through the relatively simple architectural artifacts of breathing walls, envelopes, and screens. These are fundamentally hyperobjective. They can regenerate suitable urban microclimatic layers that support multiple forms of life, and habitable and edible landscape, because they are penetrable. Therefore, they facilitate airflow for better climate comfort and habitats as well as better connectivity across the urban and architectural environment across species.

Today's discussion on breathing walls in the context of architectural performance and atmospheres starts with the theoretical work by David Leatherbarrow. The theme is discussed in relation to the argumentation for a shift within an understanding of the architectural profession, 'the architecture oriented otherwise' [26]. Around the start of this millennium, a serious discussion started on architecture's interaction with its environment, which also involves its penetrability, and biotic and abiotic agency performed through its boundaries [27,28]. At that time, the authors such as Addington, Leatherbarrow, Hensel, and others mainly sought their references in modernism, referring to architects such as Le Corbusier, Costa, and similar $[26,28,29]$. However, this might have been only due to the general acceptance of this style within the conservative society of the architectural profession. Poetic sensibility of the environmental technologies of the nineteenth and twentieth century archit ecture was investigated by Dean Hawkes through his portable 'environmental laboratory' that studied sight and hearing, with their direct relation to light and sound in the environment, but also the other senses, taste, smell and touch, separately and often in combination, that contribute to the perception of the complex experience of the environment within a building [30]. The transition between modern movement and current environmental needs in architecture were investigated by Porteous [31].

\subsection{Historical and Current Studies in the Field}

The referred modernists most likely started exploring the fields of bioclimatic architecture (not all of them will be discussed in this article) because of the political situations in countries with extreme climates. Due to the entry of modernism into different climatic, ecosystemic, cultural and political situations, it was not possible to neglect the traditional influence of those locations. Therefore, they had to adapt to the local social and climatic environment $[32,33]$. Shading and cooling systems are clearly more profuse in hot sunny climates, where they have traditionally been absolutely necessary, by themselves cooling the environment by approximately $10^{\circ} \mathrm{C}$ (based on author's measures by weather station placed into the openings).

Many of these strategies are closely linked to the culture that created them, and their relation to privacy since cultures have often come into being in a determined climatic environment [34]. Direct references to breathing walls, envelopes, and screens are substantially clear in oriental, often Arabic, architecture $[35,36]$. These are often attached to semi-interior spaces such as the 'kishks' (wooden kiosks) of a 'Turkish House' [37]. Culture, as well as biodiversity, is powered by the long-lasting evolution of self-organisation [24]. Therefore, these similar and other gradual bioclimatic layers become a critical performance for habitable and edible landscapes in more extreme climates across multiple species, including humans. Several so-called 'ecological prototypes' that stand for a new type of green construction (CG) have been studied by Sunguroğlu Hensel. These are integrated and adaptive systems of design, construction, and practices that link architecture, horticulture and agriculture, landscape, and ecology [38]. Specifically, vernacular oriental pigeon 
houses in relation to climate were investigated by Hensel and Sunguroğlu Hensel [39]. However, different bioclimatic layers of cross-species cohabitation have been common all over the planet, not just in the places with larger extremes (see Figure 1). It could be discussed if all such cases were built with such purpose. Purposeful or not, these layers play a critical role in urban connectivity and biodiversity [40]. Bricks for other species' habitations were recently installed by RSBP in Grange Pavilion, Cardiff, Wales [41]; a monarch butterfly sanctuary was designed on a Manhattan facade by Terreform One [42]; many DIY coliving adaptation projects are suggested by the Rewild My Street group in London, UK [43]. The discussion of cross-species coliving was also brought up by several art and architectural exhibitions [44,45]. As climate has recently been migrating up and down the equator, so must the schools of thoughts from diverse cultures do in order to mitigate the climate change and biodiversity loss.

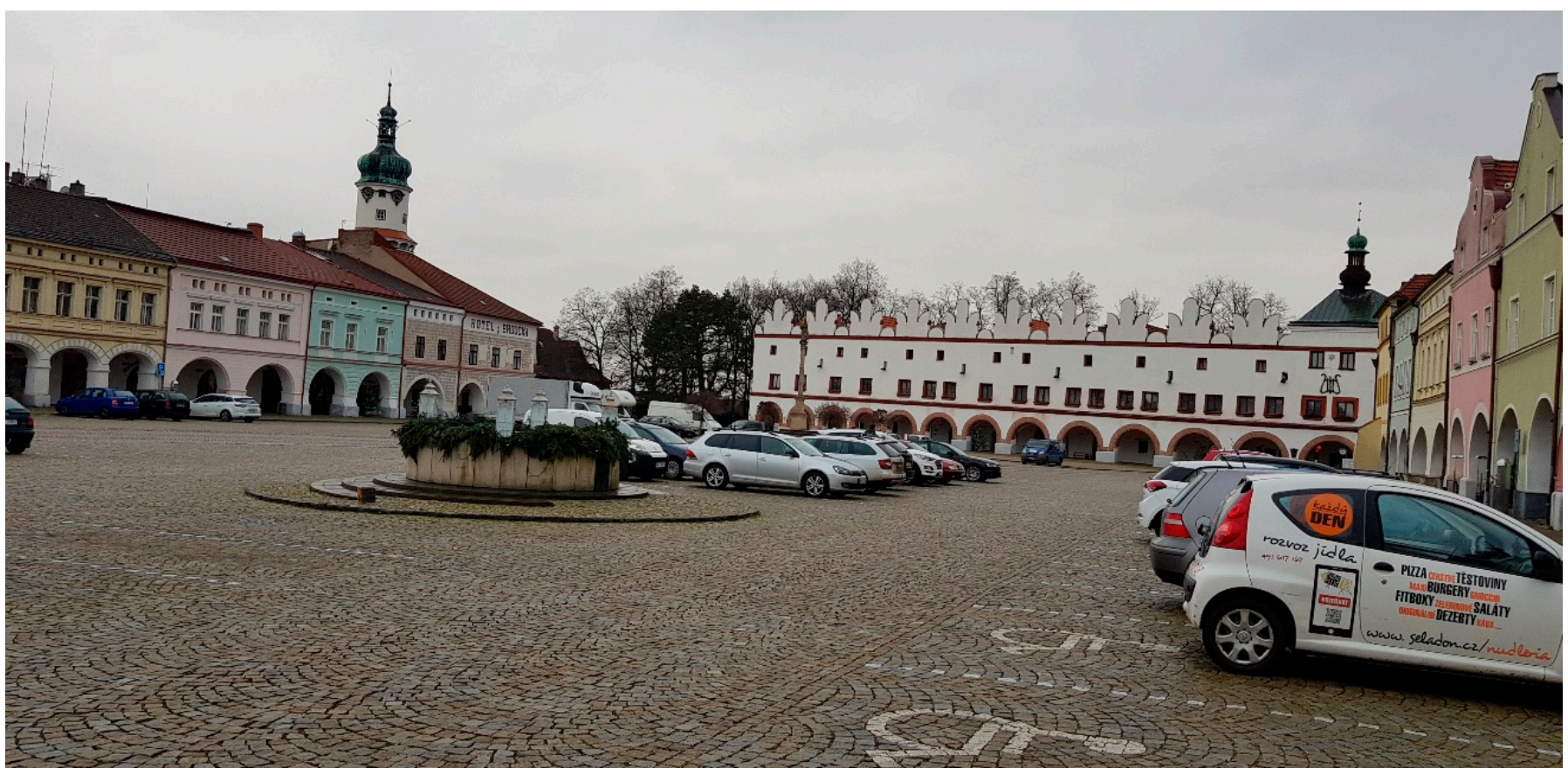

Figure 1. Semi-interior arcade spaces of a renaissance square in Nové Město Nad Metují, Czechia. These spaces have been largely inhabited by swallows. The human citizens believe the swallows bring them luck. They also lower the number of mosquitoes and are a sign of healthy environment (photo: Davidová, 2021).

\subsection{Gigamapping the Relations}

The cross-cultural gigamaps suggest (see Figures 2 and 3), that such performanceoriented oriental architectures had a critical influence on the architecture in Portugal and Spain, which then influenced the architecture in Latin America, as stated in a review by Camacho et al. [33]. Therefore, it is clear that the schools of thought are transferrable across regions when adapting to local specific situations and offering local specific solutions. This also becomes critically important with species migration towards the north and south of the equator caused by climate change (including humans). This article seeks such adaptations within the complexity of a changing world. 


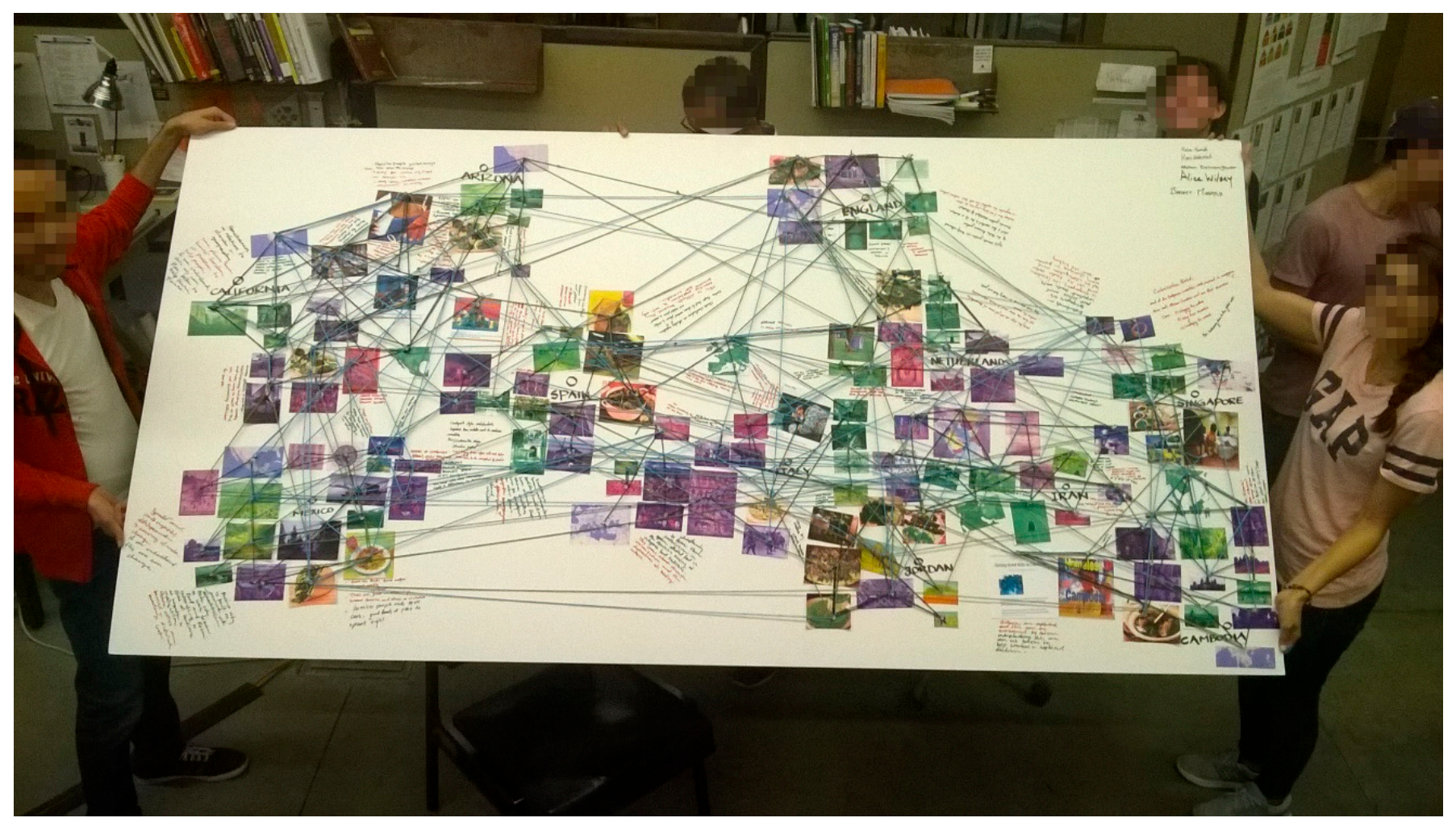

Figure 2. Gigamapping the Architectural Performance: Appreciation of New Coming Cultures workshop result at the University of Arizona [46]. The M.Sc. students with various backgrounds were mapping cultural influence flows across their countries of origin, current place and speculated futures. The gigamapping employed fields distinguished by colour coding and storytelling as an evaluation of relations (photo: Davidová, 2016).

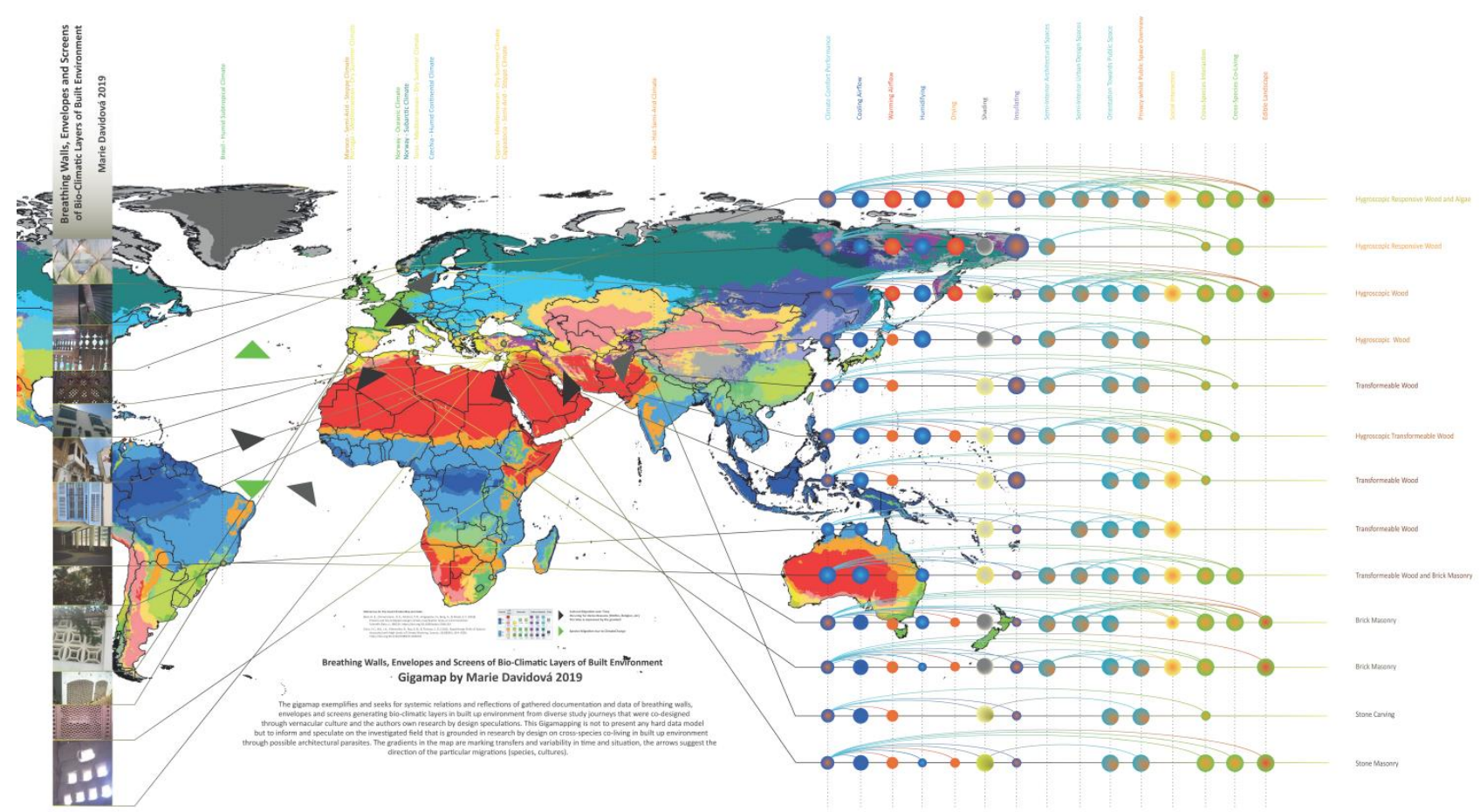

Figure 3. Breathing walls, envelopes and screens gigamap (gigamap: Davidová, 2019, Köppen-Geiger climate classification map: Beck et al. under a creative commons licence [47]). 
Gigamaps are devices for design inquiry rather than analytical tools such as those used in systems engineering or in hard systems models [48]. However, they also cover a lot of analysing aspects that perform in feedback loops between observations, analysis, tacit knowledge, and designing. It seems that today's systems view agrees with Eastern philosophy on the interdependence of all systems, which function in patterned networks, as established by organismic biology, new physics, cognitive science, ecology, and other disciplines [49]. Therefore, this article does not discuss any hard data collection, complete picture, or originality of the concept of penetrable boundaries, as it seems richly appearing across a variety of indigenous, vernacular, and traditional cultures. It seeks richness and synergy in the social, cultural, natural, material, and generally ecosystemic performance of penetrable boundaries and its variations, relevance, evolution, and pathways to adaptation to today's architectural and urban design. The article investigates the bioclimatic and socio-environmental relations of cross-species coliving in various spatial/environmental layers, 'onion peel' [50], of the built environment that is enabled through such penetrable boundaries. These are looked at as a ' ... design with a number of nested, overlapped formcontext boundaries' [51]. The article and the gigamap show that such coliving through penetrable boundaries has been common in many traditional architectures, specifically those with extreme climates [52,53]. Following a Semperian tradition [54], the article relates such coliving with material performance. However, such investigation is expanded into the advancement of cross-species and material coperformance that generates coliving situation (with or without the initial intention). The discussed examples include prototypes from Cappadocia, India, South Portugal, Brazil, Cyprus, Tunisia, Morocco, and Norway and are concluded in a synthetic speculative prototype for recent extremes of recently classified mild climate regions. This prototype can be considered as a result of this research.

\section{Methodology}

The article qualitatively identifies several schools of thought from past, often traditional, architectures and synthesises them into a contemporary design addressing recent climate change and biodiversity loss. It focuses on parameters of climate comfort performance, cooling airflow, warming airflow, humidifying, drying, shading, insulating, semi-interior architectural space, semi-interior urban space, orientation towards public space, privacy in public space overview, social interaction, cross-species interaction, crossspecies coliving, edible landscape in relation to material, climatic and cultural location, and migration. For mapping such relations, a gigamapping tool from systems-oriented design [55] is used. Gigamapping is a visual complexity diagramming and may also involve other media such as sound and videos [56]. Though gigamapping can relate soft and hard data [57], such data from this research were discussed and related in more detail in other publications by the author $[51,52,58]$. This article aims to synthesise the soft data supported by the hard data of above-mentioned studies and their direct application into the 'research by design' [59] presented and analysed through 'full-scale prototyping' [60] of responsive screen Ray. The author discussed the importance of combining gigamapping and prototyping in other publications $[56,61]$. The gigamaps map the complexity related to the prototype whilst the real-life prototypes test the complexity within the 'real-life codesign laboratory', which means that the prototypes are tested in the complexity of real-life environment [62-64]. The research analyses existing examples from the past because such prototypes were tested over generations through real life. Therefore, they developed certain schools of thought that are worth our attention. This analysis is led by a research question generated through architectural and urban design practice. It seeks to identify how architecture could address climate extremes in mild climate regions and the need to accommodate other species in an urban environment. Such a need has been recently discussed by ecologists $[40,65]$. By reflecting on systemic relations in gigamaps, full-scale prototypes, and their confrontation with real life, new design speculations appear. Therefore, this approach generates scalable creativity in research by design, and it helps dealing with the complexity of today's world. 


\section{Breathing Walls, Envelopes and Screens}

The penetrable boundaries-breathing walls, envelopes, and screens appear in various, often extreme, territories, generating socio-bioclimatic layers in the built environment that were codesigned through a variety of vernacular cultures. They generate socio-bioclimatic peels of onion, such as fences, balconies' separations, shutters, airlocks of buildings or other semi-spaces' borders or facades. While doing so, they can provide nondiscrete layers for cross-species climate comforts and social interactions with different levels of privacies (visual, sound, and smell), edible and cohabitable landscapes. Many species, including humans, have different levels of privacy needs in different spaces. For example, few people wish to have street fox visitors in their flats, while they appreciate them in their garden. We feed street birds on our balconies, while we do not want them in our living room. Similarly, we do not want unknown human visitors in our bedroom whilst we are happy to meet unknown people on a street or in a restaurant. Breathing semi-interior spaces therefore serve as a transition meeting zones across people and other species; those spaces also have climatic performance. According to Hall, two categories of the sensory apparatus can be defined: the distance receptors-eyes, ears, and nose — and the immediate receptors—skin, membranes, and muscles. These receptors have different degrees of specialization and different functional spheres [66]. The discussed semi-interior spaces should provide a transition and exchange zone between the two and its larger context of cities and their adjacent landscapes' metabolisms. They offer different levels of privacy, penetrability and thus different levels of agency and performance. Therefore, they interact with intimacy as well as with micro and macro climate comforts and food webs.

The above gigamap (see Figure 3) exemplifies and seeks systemic relations of gathered documentation, observations, and data of breathing walls, envelopes, and screens from the author's diverse study journeys and the author's own research by design speculations. These are reflected in the below subsections. The map relates different observed samples and their material, various ecosystemic performances, their climate zones and locations, historical migrations of cultures, and recent migrations of species south and north from the equator due to the climate change [67]. Many species are no longer able to live in current equatorial regions and this phenomenon is also supported by the recent architecture in these regions, such as overheated 'concrete jungles' with urban heat islands. The migration of human species, amongst all others, also involves migrations of human cultures for different climatic and political reasons. The map reawakens the atmospheres' memories through the gathered photo documentations and their relations to walls, screens, and envelopes' performance and performance speculations, relating 'what is' with 'what if' [23]. The presence and size of the dots in different categories show the proportional performance of different cases, whilst the colour coding refers to an easy orientation such as blue for cold and red for hot. This gigamapping is not to present any hard data model, but to inform and speculate on the investigated field, grounded in research by design on cross-species coliving in the built environment, through possible architectures and architectural and urban design parasites, such as breathing screens, envelopes, and walls or more penetrable installations. The gradients in the map mark transfers and variability in time and situation; the arrows suggest the direction of the particular migrations (species, cultures).

The variety of the selected cases shows different performances in different locations and cultures with their specificities. It shows samples with higher or lower climatic performances, habitation opportunities, or edible landscape support. These parameters (from left to right: climate comfort performance, cooling airflow, warming airflow, humidifying, drying, shading, insulating, semi-interior architectural space, semi-interior urban space, orientation towards public space, privacy in public space overview, social interaction, crossspecies interaction, cross-species coliving, and edible landscape; on the side the material production is expressed) are appearing in different relations, values, and explicitly. The samples are a selection of the author's study journeys that informed her research by design on a responsive wooden screen 'Ray' [3] discussed in the later section of the article. 


\subsection{Cappadocian Breathing Walls}

The early Christian cultures' (followed by others) cave dwellings in Cappadocia (semiarid steppe climate) developed a specific model of coliving with pigeons (see Figure 4) due to political and climatic reasons. The pigeon spaces that are in caves situated above the human spaces generate natural ventilation through their shaft connection through the stack effect. This situation occurs because the spaces that the pigeons heat cocreate the airflow. The air that is hotter than the outdoor environment is forced to exit through the breathing walls. In addition, the pigeons' excrements were at that time used as fertilisers for the otherwise arid land, enabling the culture to survive [68]. A similar situation appeared for other rich pigeons' cultures that were/are provided opportunities of habitation in otherwise rather extreme climate and terrain conditions with extremely hot summers and cold winters. The detail from the gigamap (see Figure 5) shows various ecosystemic coperformances of the brick-built breathing walls of these caves. It suggests that the wall participates in cogeneration of climate comfort for the related climate zone, edible and habitable landscape, and cross-species interaction for the symbiotic dwelling between humans and pigeons, whilst offering privacy in a difficult political situation. Such systemic dependencies cogenerate the metabolism of the cross-species settlement that would otherwise hardly sustain the conditions. The stone material provides the opportunity to mask the settlement and the sizes of the porosity are built to accommodate the pigeons who are protected from climate as well as from the predators.

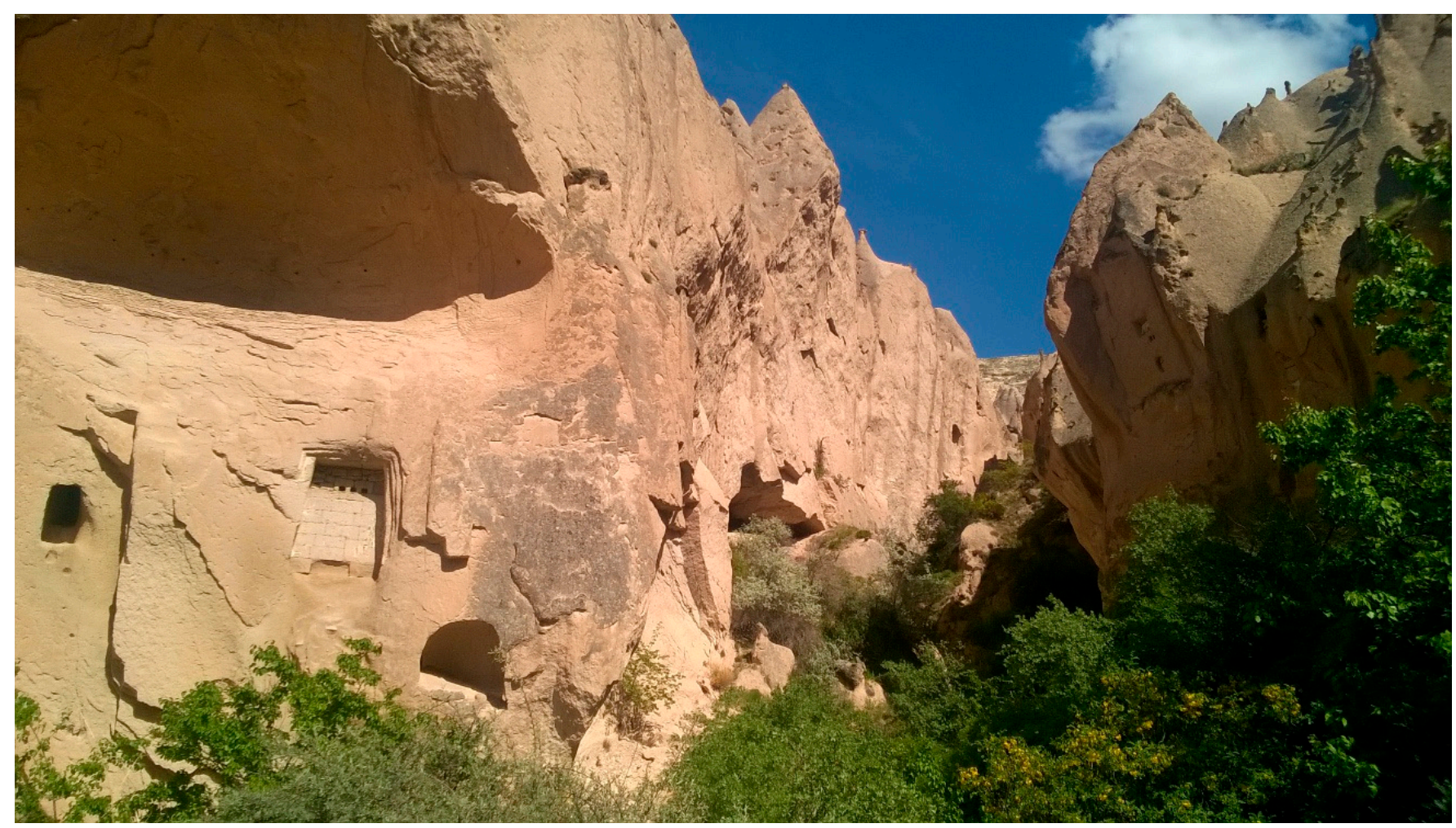

Figure 4. Pigeon houses (see the breathing wall on the left side of the picture) in Zelve valley (photo: Davidová, 2016). 


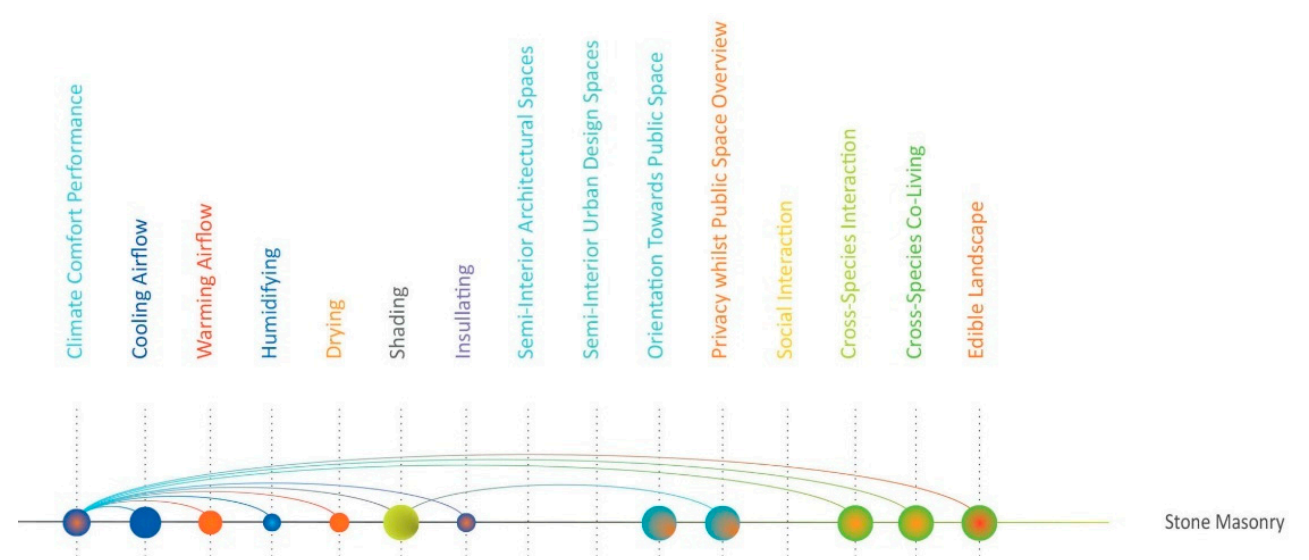

Figure 5. The detail of the gigamap showing ecosystemic performance of the breathing wall of a pigeon house in Cappadocia (gigamap: Davidová, 2019).

\subsection{Jaali}

Indian jaalis appear either in the form of breathing walls, carved stone (see Figure 6) or latticework screens with a wide range of porosity. The size of the openings and the selection of material depends on the targeted climatic performance and the availability of the material in the region. Therefore, it depends on its climate zone, in certain Indian regions with a variety of humidity and temperature levels ranging from arid to tropical and very hot to very cold [47], as is clear from Figure 3. The climatic performances of jaalis and their atmospheres are closely related to culture in reference to coliving and coperformance with nature, social intimacy, and security level (or even gender-based apartheid), and religion-related geometrical patterns [69]. Purposefully or not, nature, such as plants or insects and smaller animals, penetrates through such screens, and such coliving situations are overly understood as part of the Indian culture, being symbolic for different shrines or integrated into traditional cities' metabolisms (i.e., sacred cow milking on the streets, rat shrines, etc.).

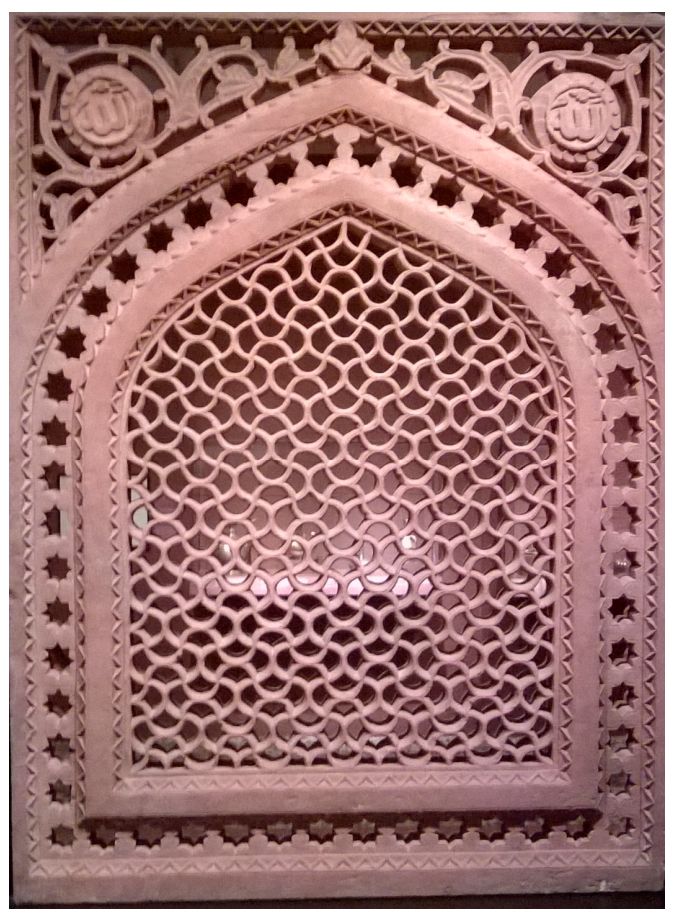

Figure 6. Jaali, Delhi (hot semi-arid climate), India, 1605-1627, Houston Museum of Fine Art, USA (photo: Davidová, 2016). 
The detail from the gigamap (see Figure 7) shows speculated ecosystemic performance of the jaali in the picture above (see Figure 6). In the not too dry conditions of Delhi with monsoon rains, it does not cover too much of the humidifying performance. Therefore, the stone material is used for generating climate comfort. The cultural purpose of the building where it is used, the mosque, requires certain privacy and intimacy towards public space and spiritual-, climate-, light- and pattern-related atmosphere. Unlike other religions at that location, it does not integrate much cross-species interaction and focuses more on the social and climate comfort and specific spiritual atmosphere. Therefore, the porosity of this screen is very dense with small openings. This is an example of this focus in this article.

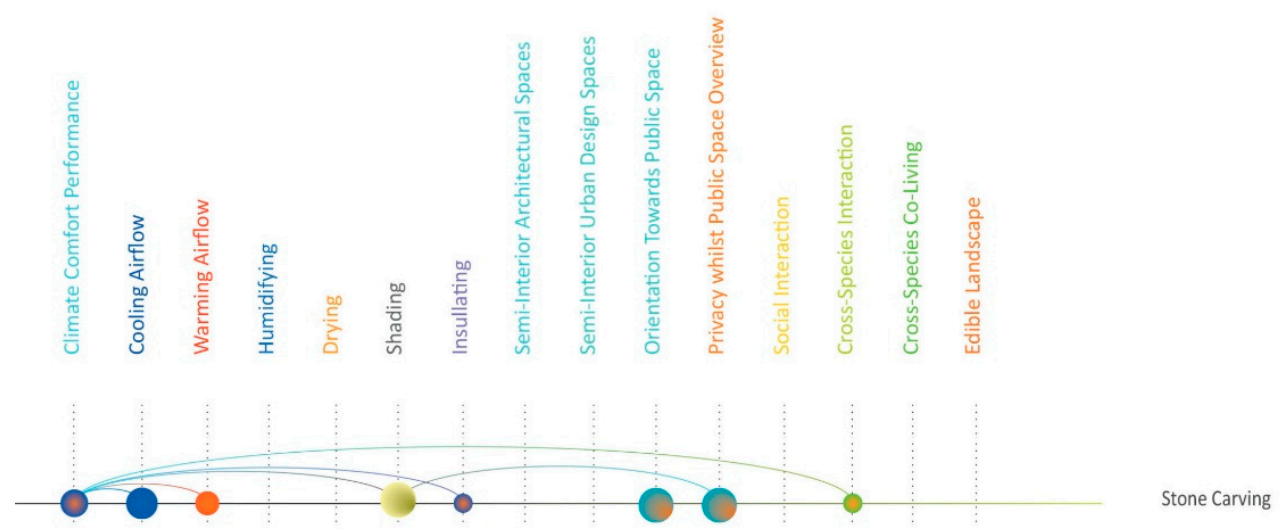

Figure 7. The detail of the gigamap showing ecosystemic performance of the breathing screen jaali from Figure 5 (gigamap: Davidová, 2019).

\subsection{Portuguese Breathing Walls}

In South Portugal in the Mediterranean dry summer that was under Moorish influence, it is possible to map ceramic breathing walls and lattice works that became a typical aspect of the local architecture (see Figures 8-11). These breathing walls are used for fences (see Figure 10), terraces, windows filling, or walls of semi-interior spaces (see Figure 8). Therefore, they support the circulation of humidified ocean air across the local bioclimatic layers of the built landscape. The airflow is magnified through these structures and cooled by ca. $10^{\circ} \mathrm{C}$ in the case of a single fence in the dense city (personal weather station measures in the summers of 2016 and 2017), cooling the crown of a tree. Thanks to their existence, people can grow plants and produce nutrients in the otherwise overheated centres of their settlements (personal observation in the summers of 2016 and 2017-see Figure 10). Their porosity also allows for certain species sizes (i.e., hedgehogs, small birds, bats, bees, wasps, and butterflies), distribution, and habitation and a certain level of privacy and social interaction. 


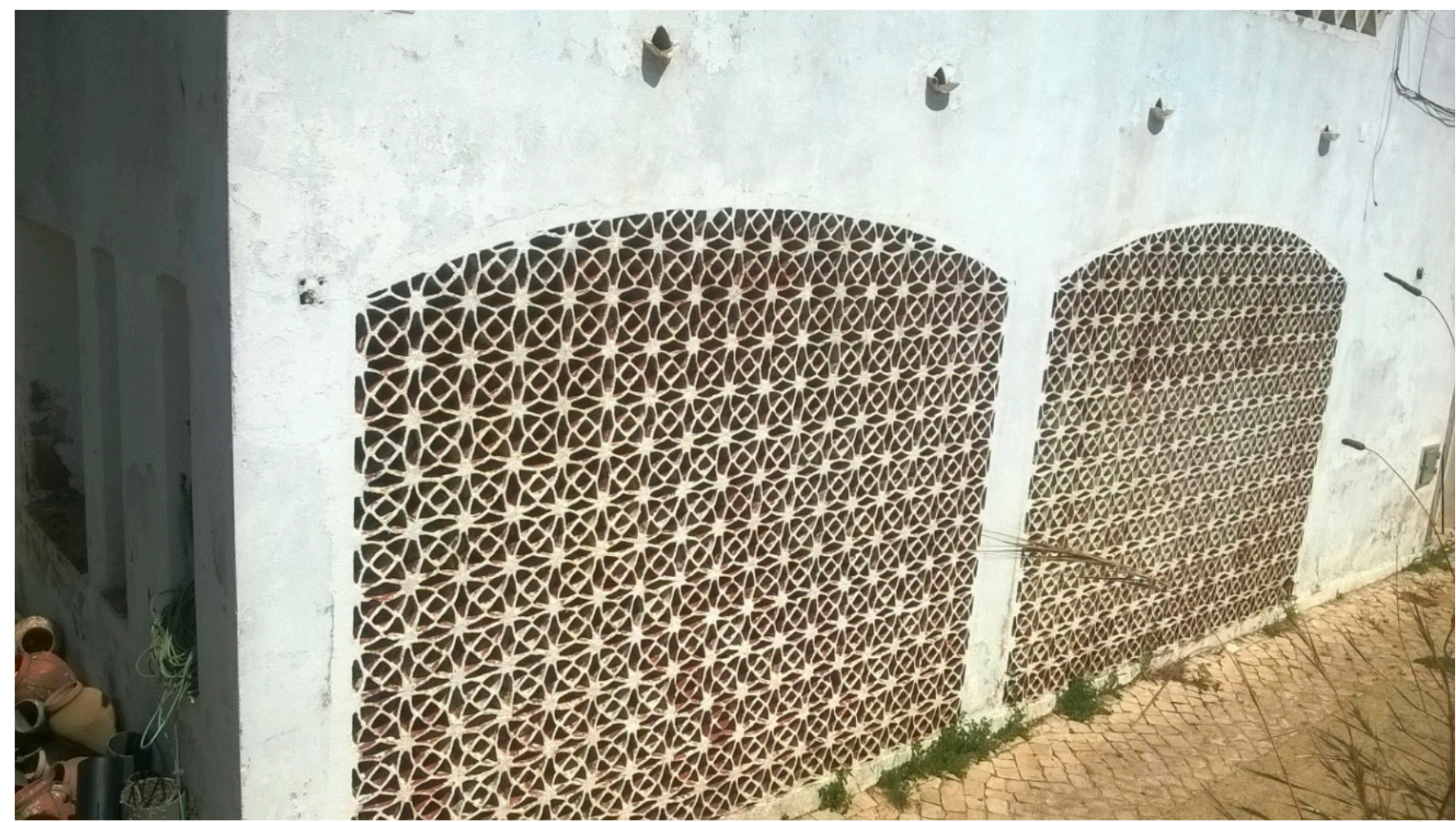

Figure 8. The breathing wall generates a bioclimatic comfort layer for a working and storing semi-interior space, village of Salema, South Portugal (photo: Davidová, 2017).
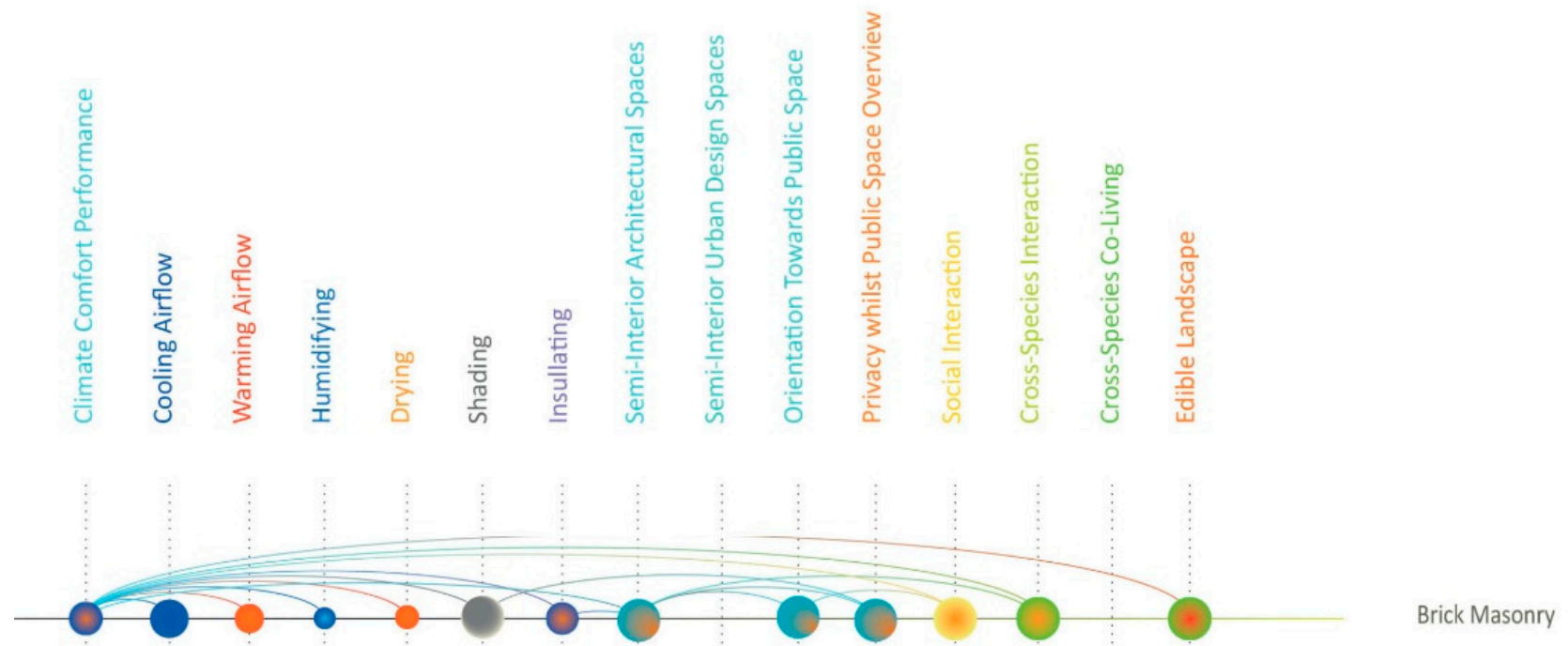

Figure 9. The detail of the gigamap showing ecosystemic performance of the breathing wall from Figure 8 (gigamap: Davidová, 2019). 


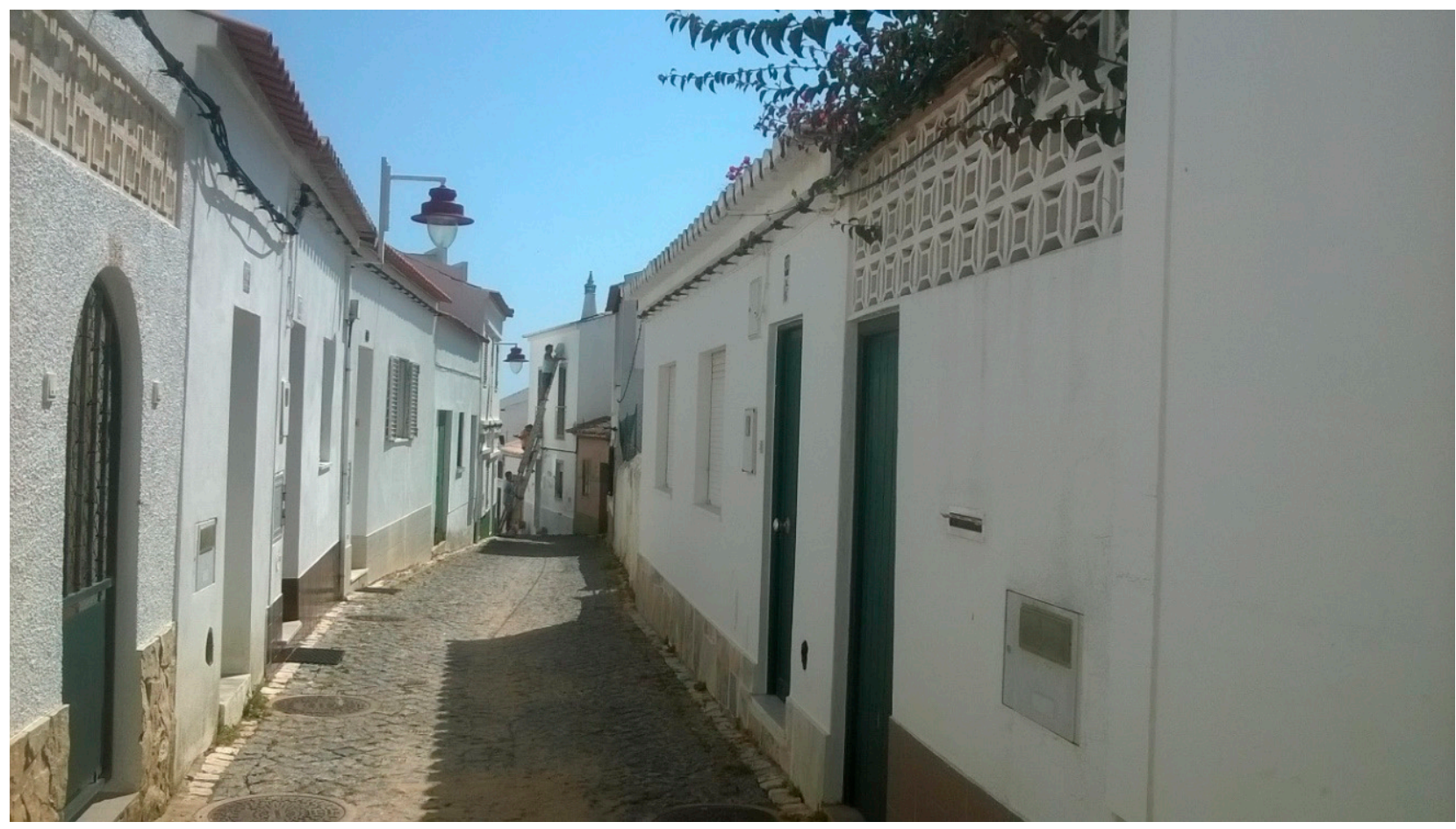

Figure 10. A courtyard bounding breathing wall generates bioclimatic layers for edible landscape in built environment, village of Salema, South Portugal (photo: Davidová, 2017).
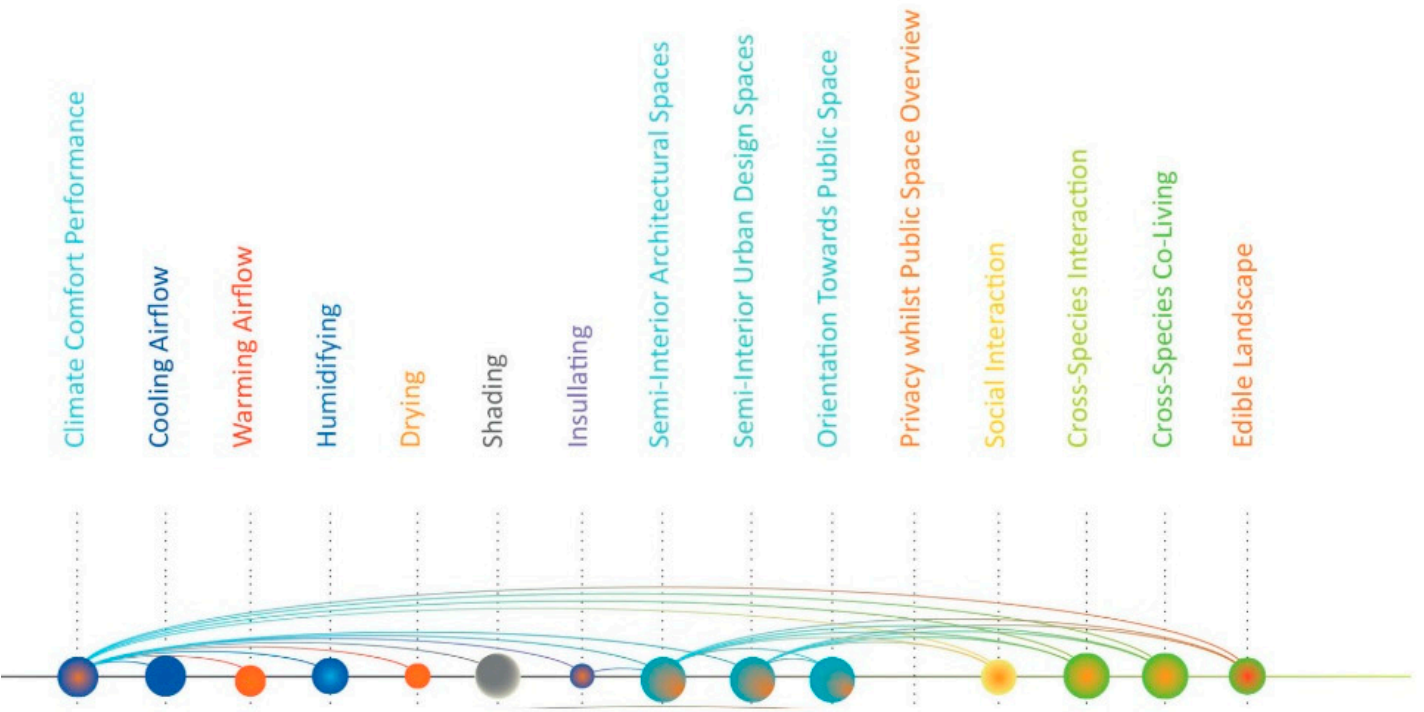

Brick Masonry

Figure 11. The detail of the gigamap showing ecosystemic performance of the breathing wall from Figure 10 (gigamap: Davidová, 2019).

The detail from the gigamap in Figure 9 shows the ecosystemic performance of the bounded semi-interior layer of otherwise mainly fully enclosed building. Its performance is to generate climate comfort and intimacy for mainly heavier physical work and storing activities for humans, whilst it offers cross-species interaction and nutrient storage, and therefore provision opportunities through its penetrable boundaries. It is therefore a typical example of cross-species interaction opportunity space.

Figure 10 shows how breathing walls are used in urban design to lower the temperature of an urban heat island. Whilst not reducing the owners' privacy, the porous wall generates airflows and the tree's boundary penetrates into a public space, bettering the local microclimate and communicating the courtyard's environment to the public. Due to 
such private space porosity, the generated climate comfort and edible landscape (cooling the tree), both public and private, take a critical part in the city's metabolism that consists of the mentioned layers, such as in Figure 8. The detail from the gigamap in Figure 11 shows how the climate comfort relates to the cross-species habitation and interaction whilst generating edible, partly public, landscape.

\subsection{Cobogós and Brise-Soleil}

Whilst there are also indigenous references, the Brazilian breathing wall 'cobogó', adapted for Brazil's humid subtropical climate, originates from the combination of modernity (concrete) and Moorish traditional techniques (muxarabis, lattices, and kneecaps). It emerged from the need to adapt the architecture to the climate, with a compositional language that represents the modernity of the new times resulting in an adequate constructive solution [33]. However, the word cobogó now relates to different material-based breathing brickwork, such as ceramics (see Figure 12).

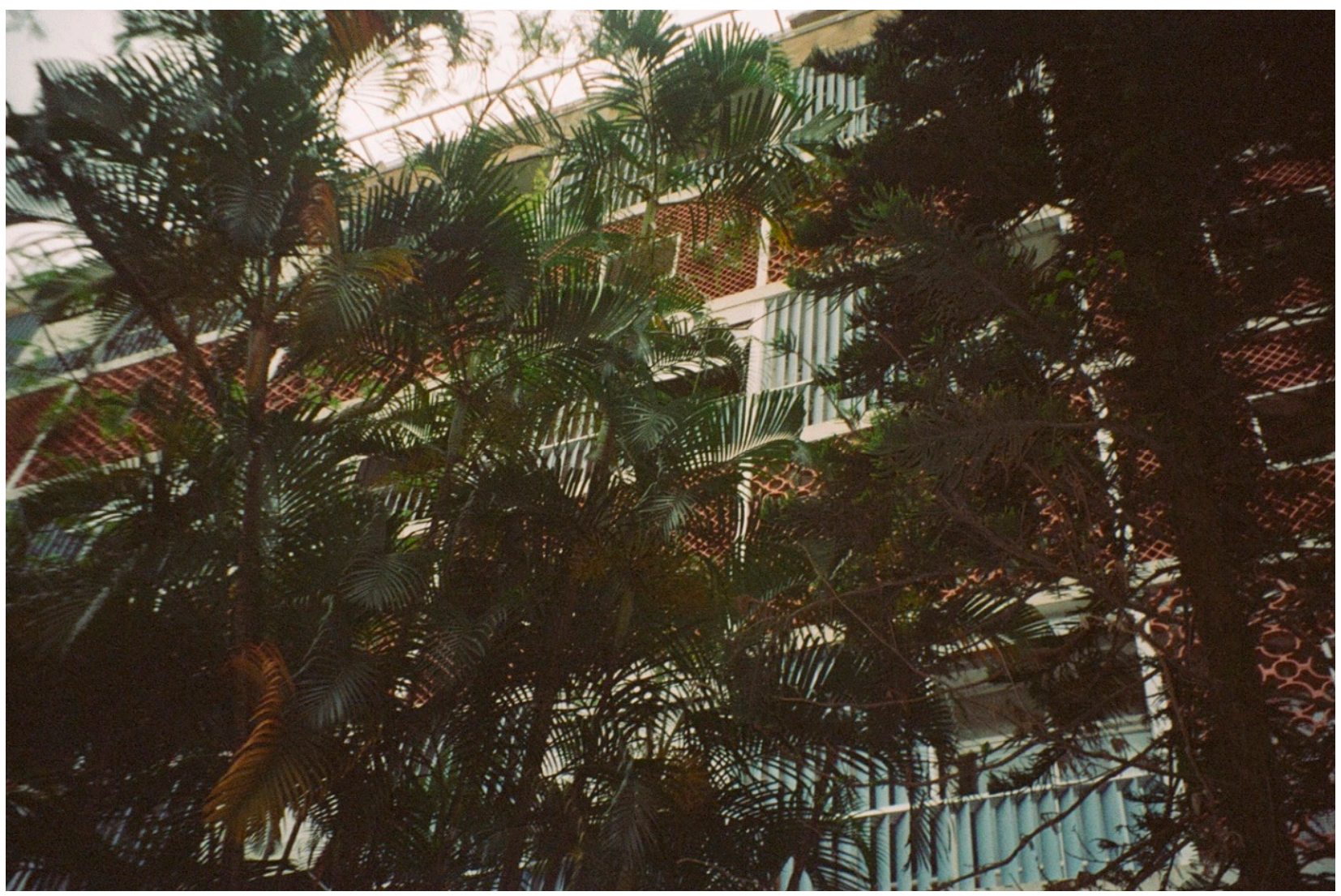

Figure 12. Costa, Parque Guinle, Rio de Janeiro, 1947-1953, combination of cobogós, an operable 'brise-soleil' moderating a microclimate, and letting vegetation grow into semi-interior spaces of an apartment block (photo: Davidová, 2005).

The above combination of cobogós and operable 'brise-soleil' by Costa (see Figure 12) offers a variety of performances for the habitants' dwelling selection. Whilst the operable screens offer a variety of boundary penetrations of sun, air, and privacy, they require more service and are often fragile. The cobogós, in this case, offer an option of full openness in their centres and a semi-level of privacy and shade on the edges. Being attached to balconies, they generate semi-interior urban design, partly public spaces for cross-species interaction, and coliving within a previously discussed onion layer. Therefore, they have the potential to take full part in the city's metabolism, offering habitats for multiple species, such as birds and insects (see the gigamap detail in Figure 13). Such balconies might therefore provide shelters from Brazilian heavy rains for nesting, etc. 


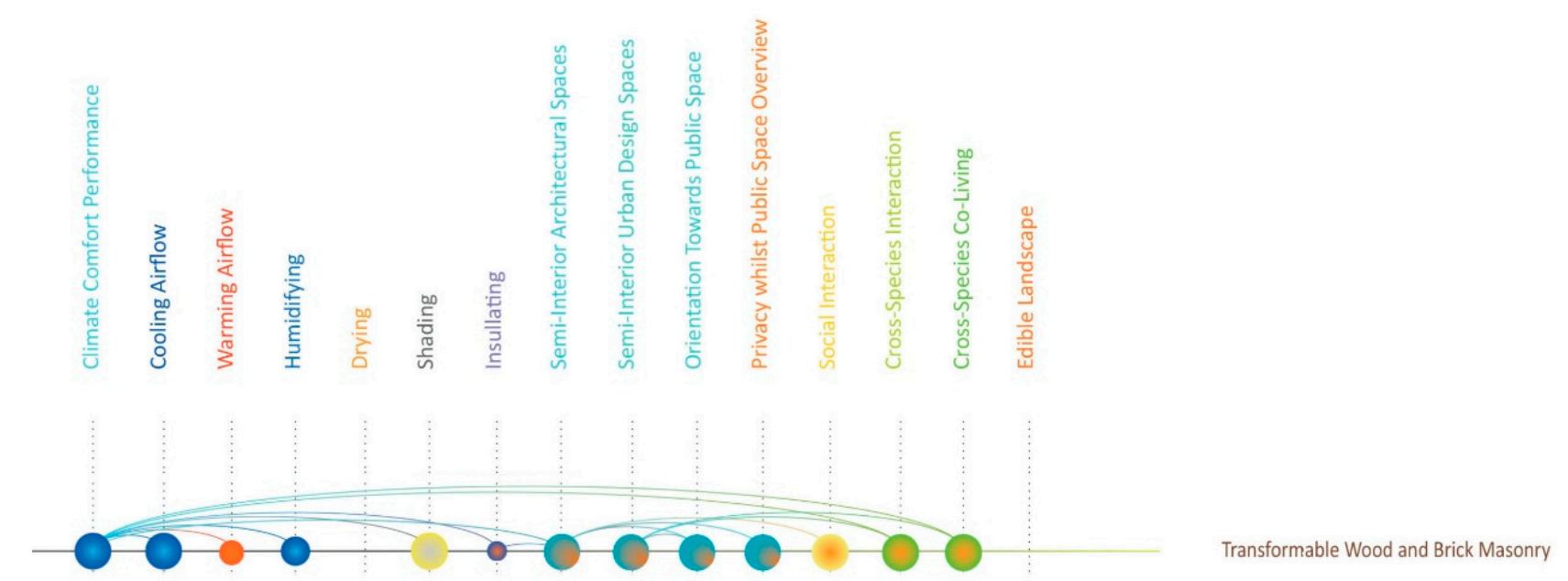

Figure 13. The detail of the gigamap showing ecosystemic performance of the combination of cobogós and an operable 'brise-soleil' from Figure 12 (gigamap: Davidová, 2019).

As opposed to the above example, the 'brise-soleil' of the Ministry of Education and Health from Le Corbusier, Lucio Costa et al. (see Figure 14) merely has microclimatic shading and visual intimacy performance. However, in terms of an urban design, they positively affect lowering the temperature of heat islands by reflecting the airflow, therefore cooling the outdoor environment. Consequently, they also have a positive effect on the surrounding ecosystem, which has bioclimatic performance itself. However, as you can see on the gigamap's detail, this performance is very limited, and does not follow the concept of coliving (see Figure 15).

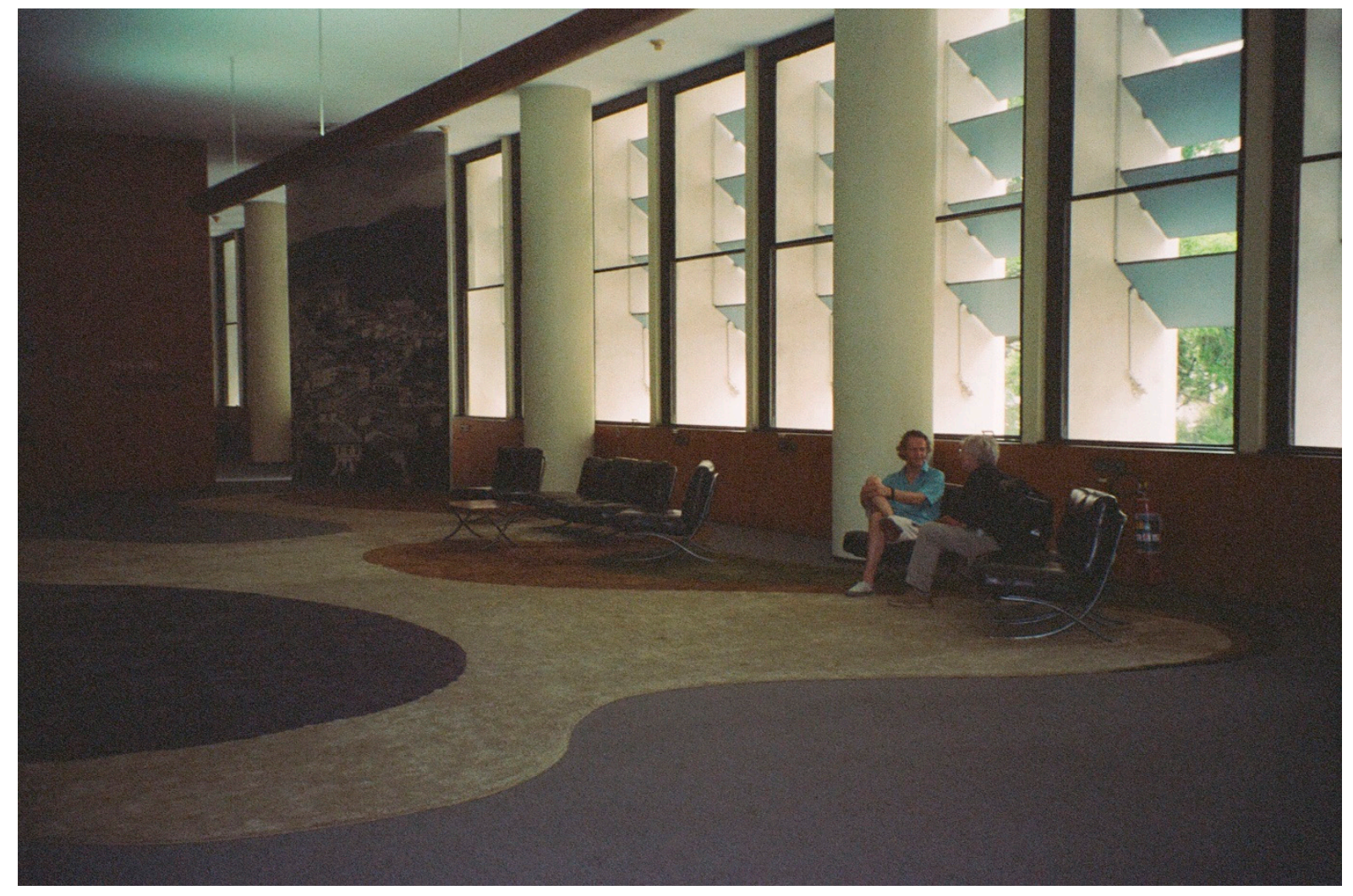

Figure 14. Le Corbusier, Lucio Costa, et al., Ministry of Education and Health, Rio de Janeiro, 1937-1942, operable outdoor jalousie, 'brise-soleil' (photography: Davidová, 2005). 


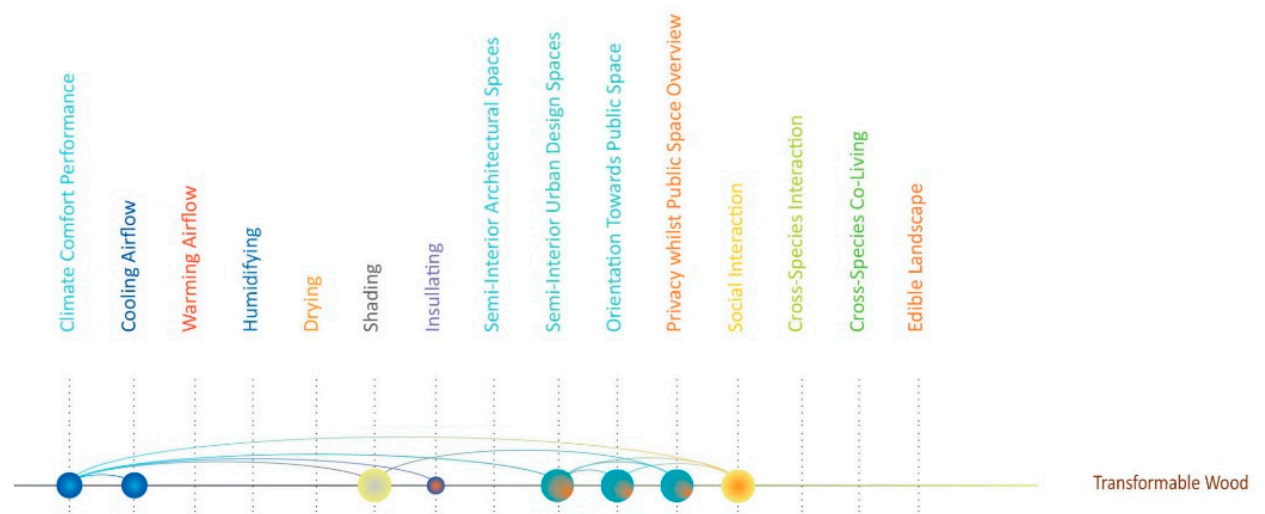

Figure 15. The detail of the gigamap showing ecosystemic performance of the operable 'brise-soleil' from Figure 14 (gigamap: Davidová, 2019).

\subsection{Transformative Shutters}

Transformative shutters are spread across all Mediterranean cultures, specifically those with dry summer and most likely developed from the mashrabiyas, discussed in the following subsection. These shutters can regulate the type of preferred penetrations either through operating their lamellas or through the opening and closing of the shutters (see Figure 16). Therefore, they can offer various targeted privacy, social interaction, light, shading, and airflow (see photographs and gigamap details in Figures 16-19). This type of device is very human-centred. It places the human user in control of the boundary, and therefore of the climate and privacy comfort, and other species penetration. On the other hand, the more interesting interpretation of the device would suggest that this boundary is a transformative system ready to adapt through transformation for the apparently coming conditions of climate and cross-species interaction. This, however, needs to happen in interaction with the purely 'human user'.

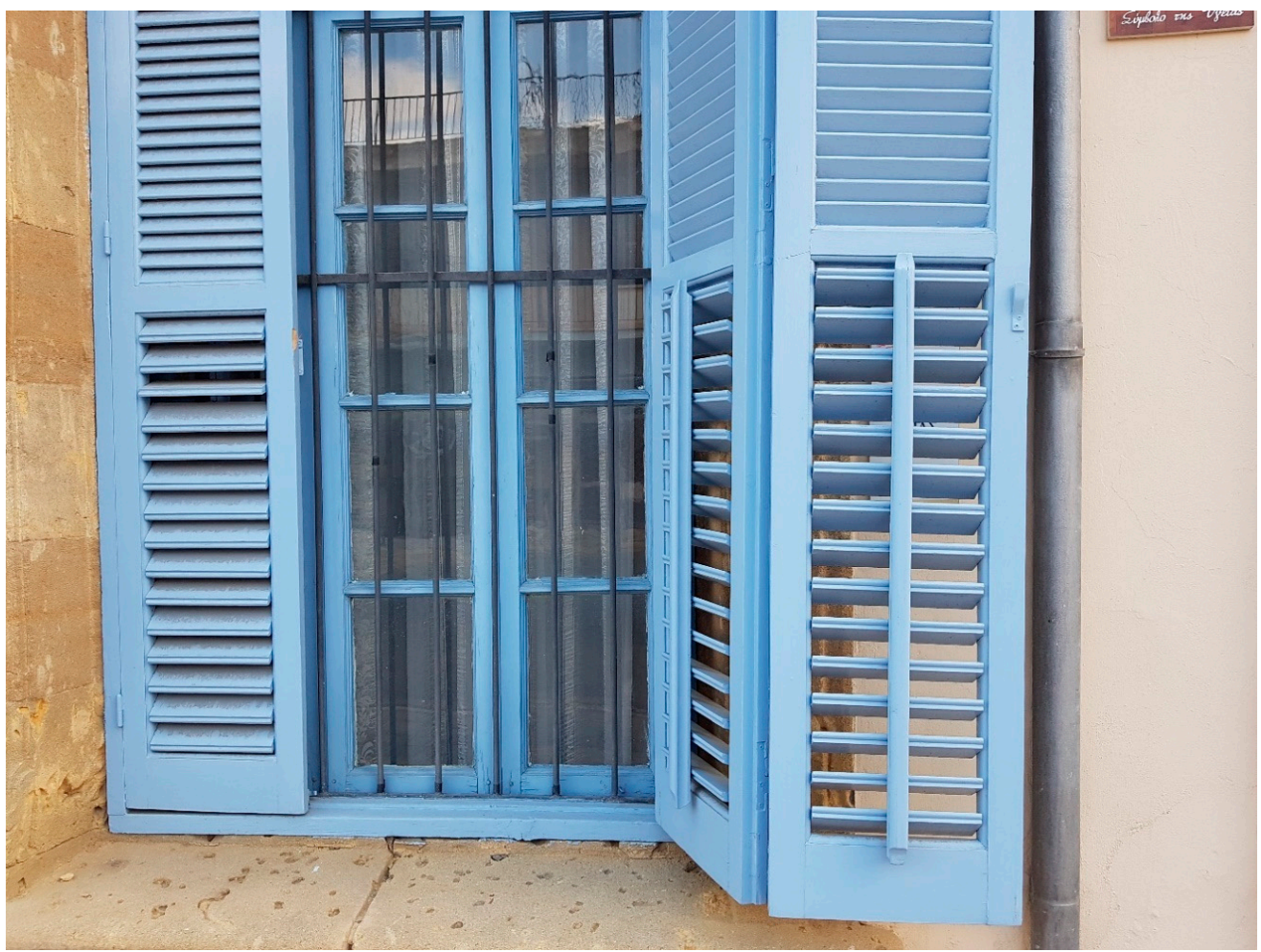

Figure 16. Transformative shutters, Nicosia, Cyprus (photo: Davidová, 2018). 

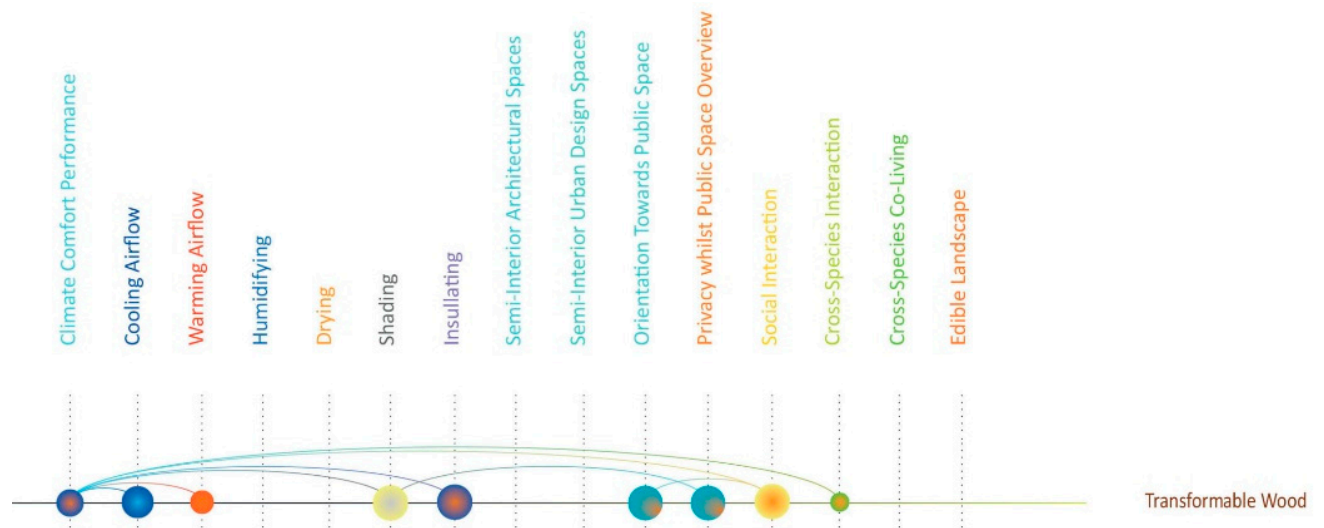

Figure 17. The detail of the gigamap showing ecosystemic performance of the transformative shutters from Figure 16 (gigamap: Davidová, 2019).

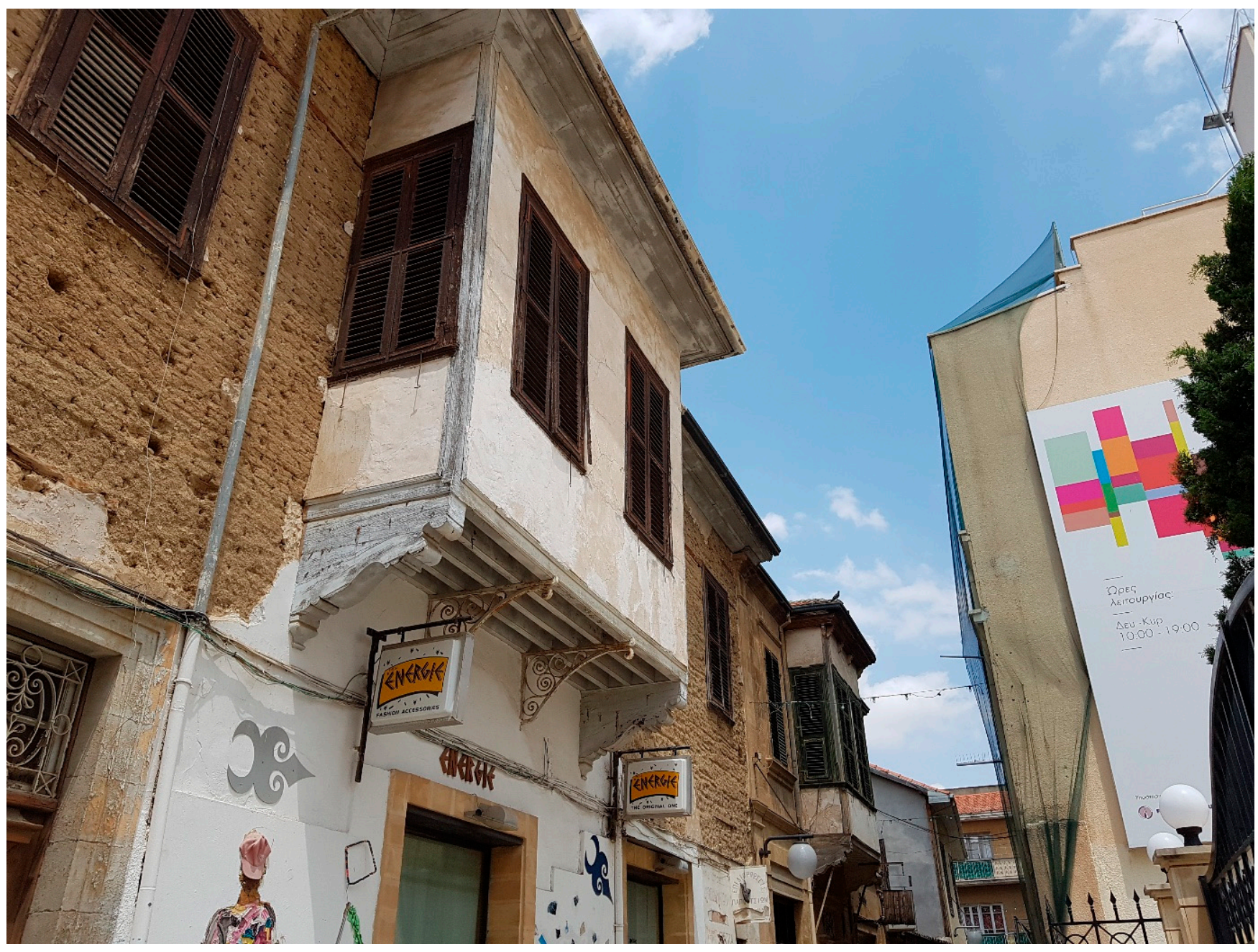

Figure 18. Kishk, the cantilevered space typical of Turkish houses, with transformable shutters with hygroscopic performance, Nicosia, Cyprus (photo: Davidová, 2018). 


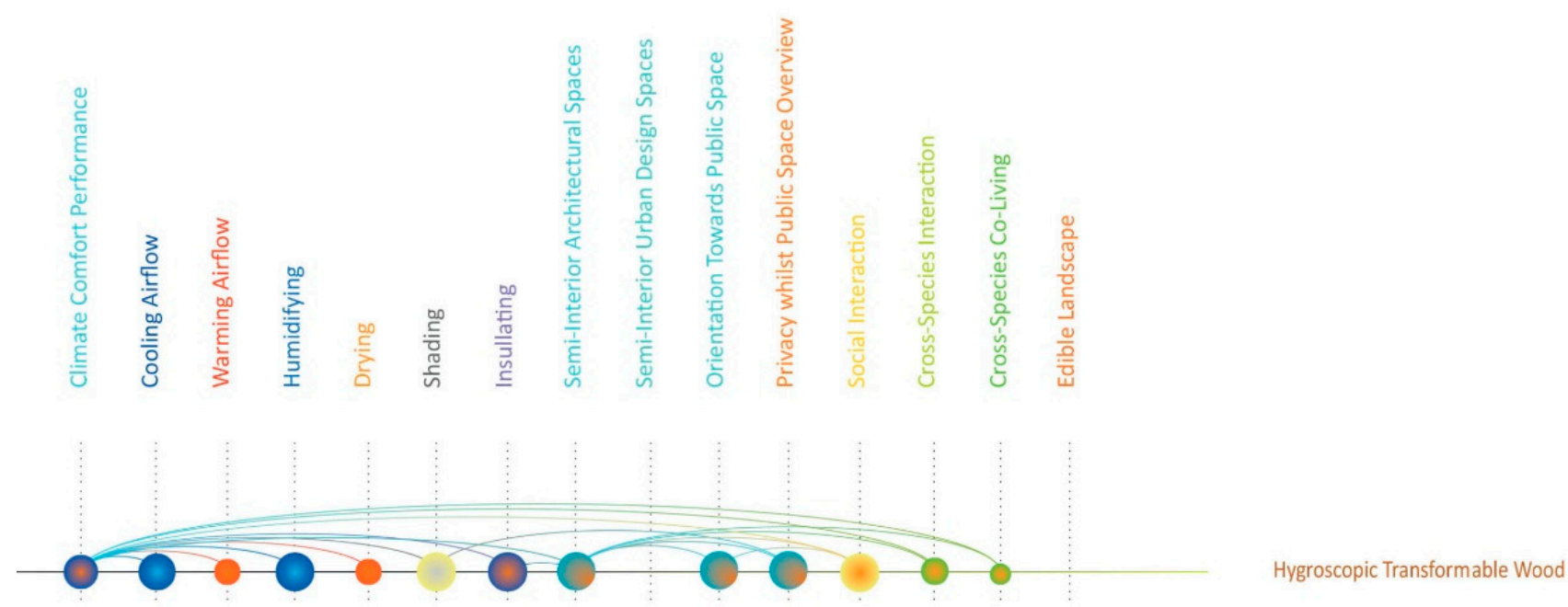

Figure 19. The detail of the gigamap showing ecosystemic performance of the transformative shutters with hygroscopic properties from Figure 18 (gigamap: Davidová, 2019).

The unpainted option of the shutter also offers nonhuman-centred humidification of the circulated air (see a photograph and gigamap detail in Figures 18 and 19, respectively). This combination of synergy between human- and nonhuman-controlled system suddenly starts to be more interesting. Moreover, in oriental architecture, the cantilevered enclosable semi-interior space kishk that is covered by those screens offers one more bioclimatic and privacy building layer with one more transformable bioclimatic regulation [37]. That one may also motivate the potential of cohabitation across different species, specifically pollinators. This is because most species do not like to share the heart of their dwelling with other species. Therefore, they prefer to share the spaces between human habitats (semi-interior ones) rather than their dwellings.

\subsection{Mashrabīyas}

The oriental lattice screens, so-called mashrabīyas (see Figures 20-23), whose performance towards wood's hygroscopicity was largely investigated by Hasan Fathy [35], are common across arid, semi-arid, and Mediterranean climates. The urban fabric and its architecture in such locations are generated by layering penetrable and vapour evaporative bioclimatic layers. The public space oriented semi-interior spaces suitable for inhabitation of various species of pollinators are covered by mashrabiyas. These are often combined with spaces that can be operated by enclosable windows (see Figure 20). This leads to spaces with ventilation chimneys or openings towards a courtyard with plants and a fountain. Many of the mashrabiyas are untreated to absorb the night humidity evaporated into the airflow passing through these layers on hot, dry afternoons (see Figures 22 and 23). The screens regulate different types of penetration from the street, including climate, privacy, and small species such as insects that the inner gardens might attract with fountains and the better climate of such types of architectures (see gigamap details in Figures 21 and 23). The bioclimatic layers of such dwellings have a larger positive coperformance impact on the often very dense and dry metabolism of oriental cities and provide a spiritual atmosphere in the interior. 


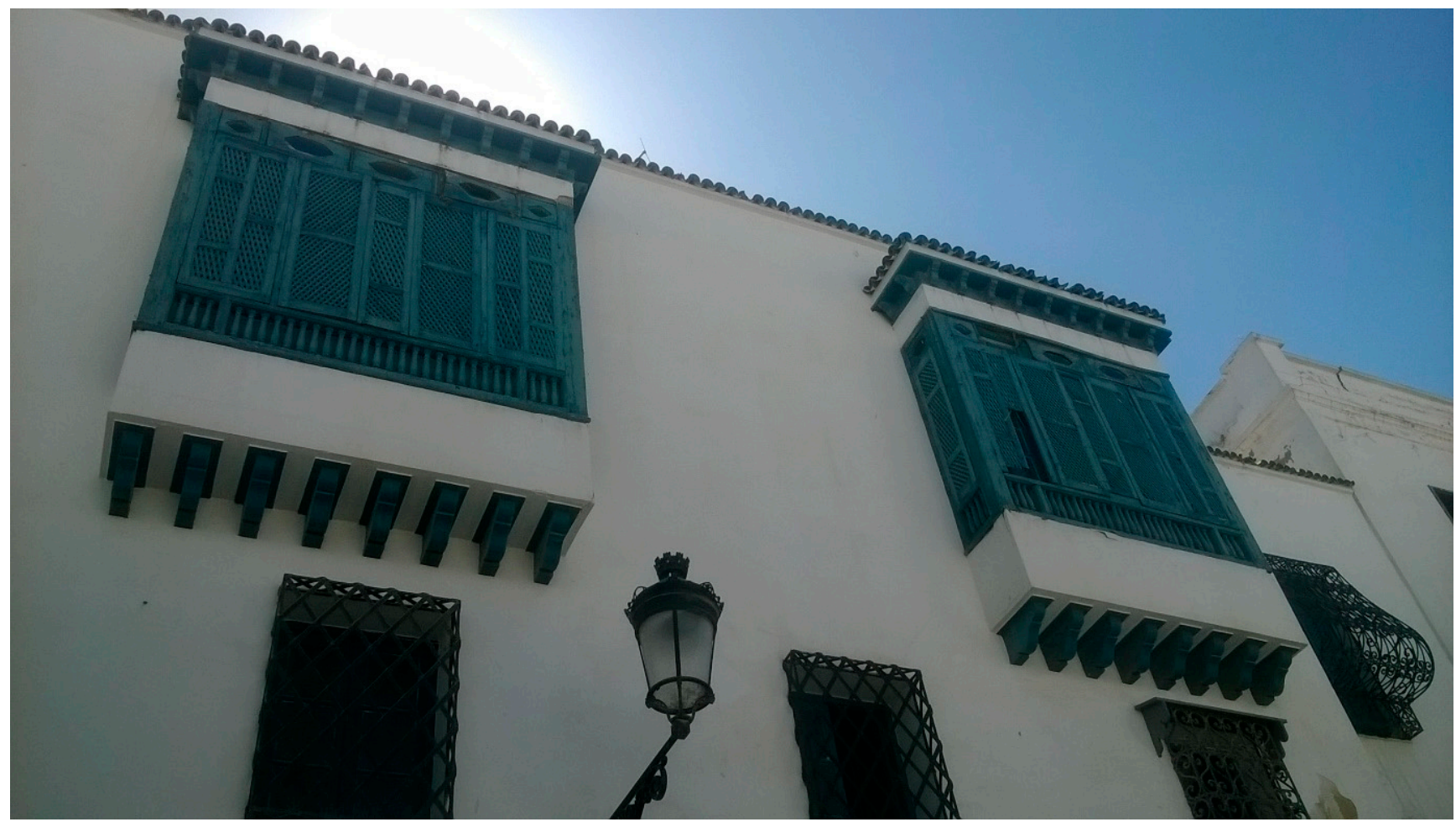

Figure 20. Kishk is a cantilevered space typical for a 'Turkish House' that is often enveloped by mashrabiya [37] in Mediterranean climate of Tunis (photo: Davidová, 2017).

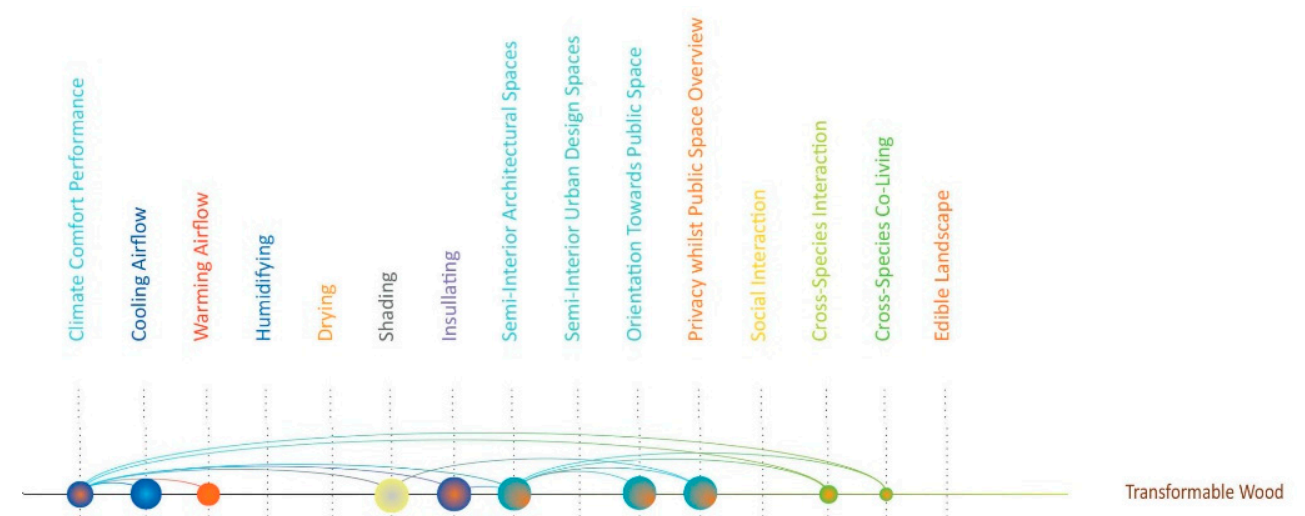

Figure 21. The detail of the gigamap showing ecosystemic performance of the 'Turkish House' with mashrabīya from Figure 20 (gigamap: Davidová, 2019). 


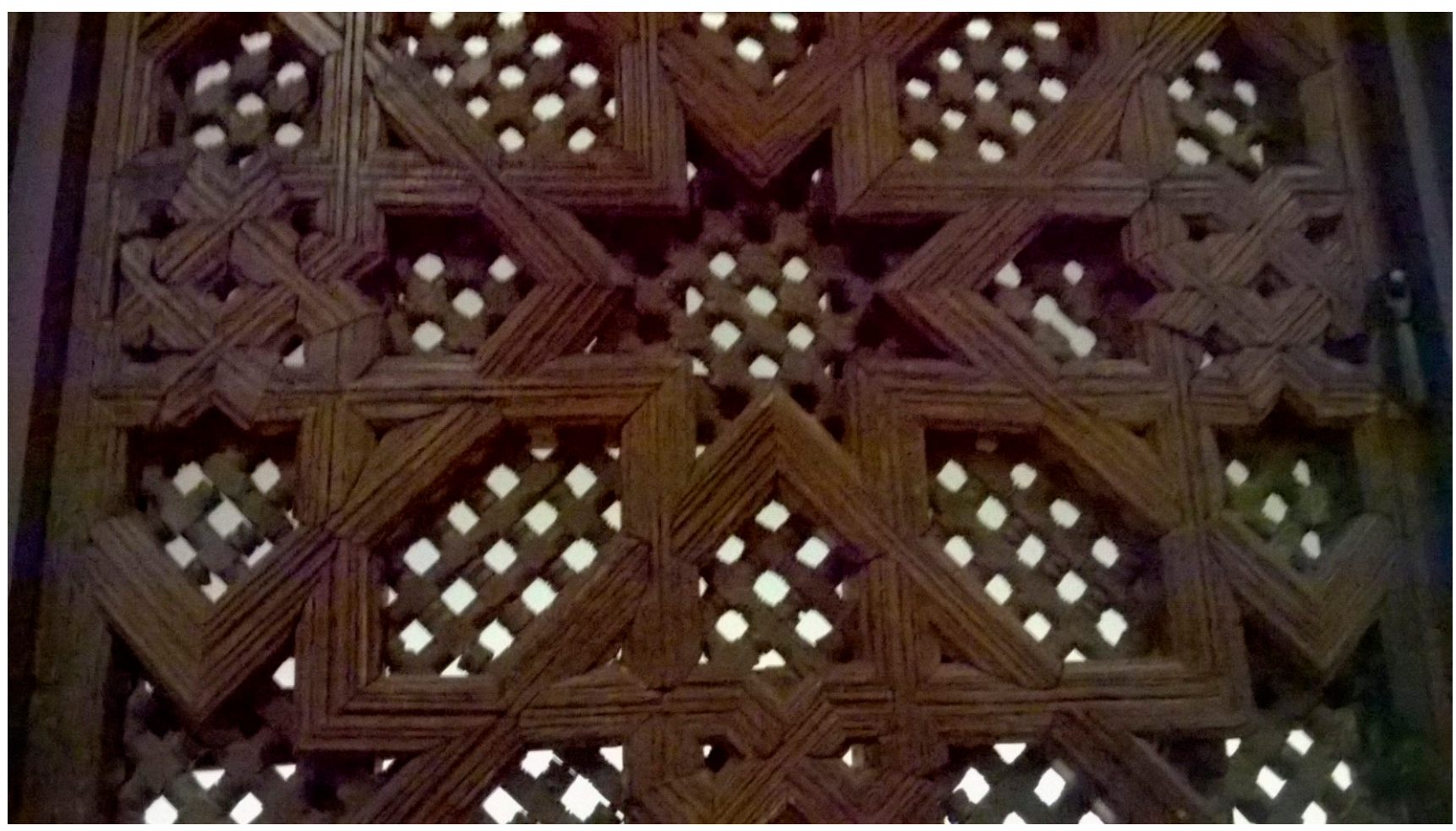

Figure 22. Moroccan mashrabīya (semi-arid climate) from 15th century, Houston Museum of Fine Art, USA—desert climate (photo: Davidová, 2016).
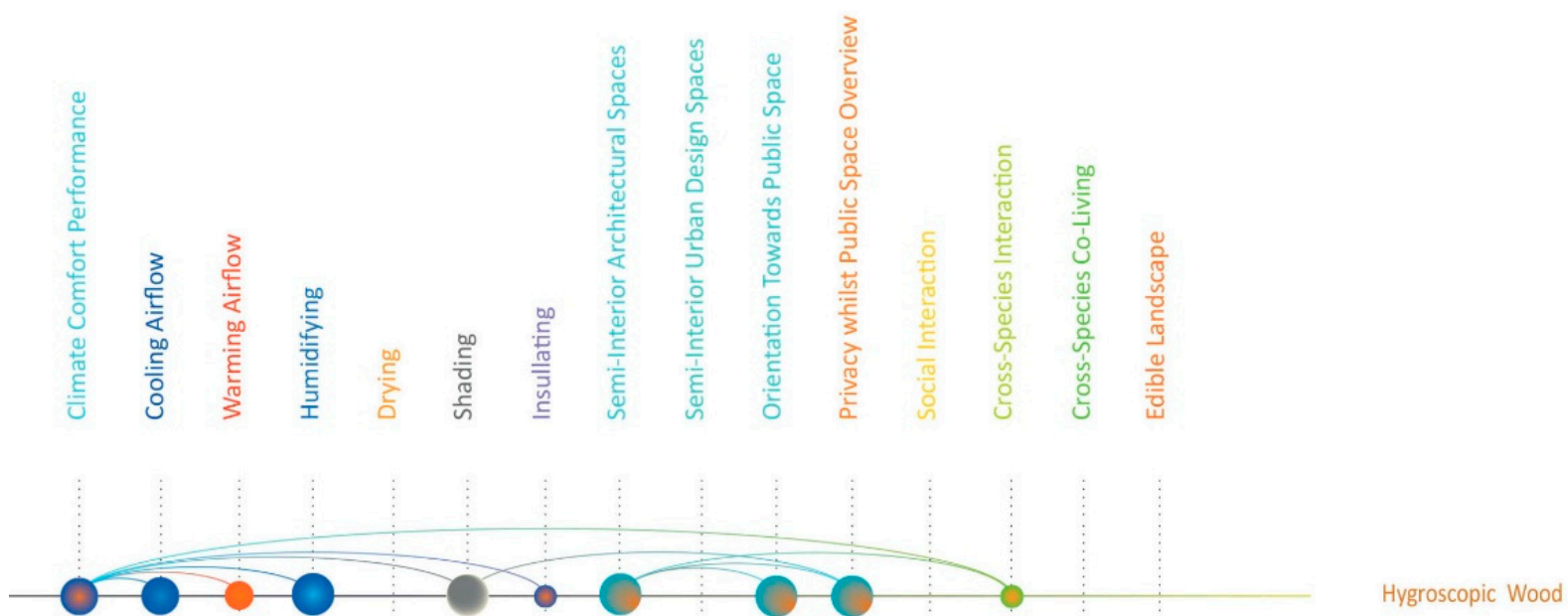

Figure 23. The detail of the gigamap showing ecosystemic performance of the mashrabiya with hygroscopic properties from Figure 22 (gigamap: Davidová, 2019).

\subsection{Scandinavian Breathing Screens and Envelopes}

The wooden Scandinavian breathing screens and envelopes are semi-bordering, multipurpose, and communication spaces, so-called svalgangs (see Figures 24-27), and storing and working spaces called skuts. They also often envelop the main structure of the building. They are often enveloping three or all sides of the building simultaneously [52] (see Figure 26). In some cases, their performances are influenced by their microclimate through the material responsiveness when warping due to relative humidity and temperature (see Figure 26). 


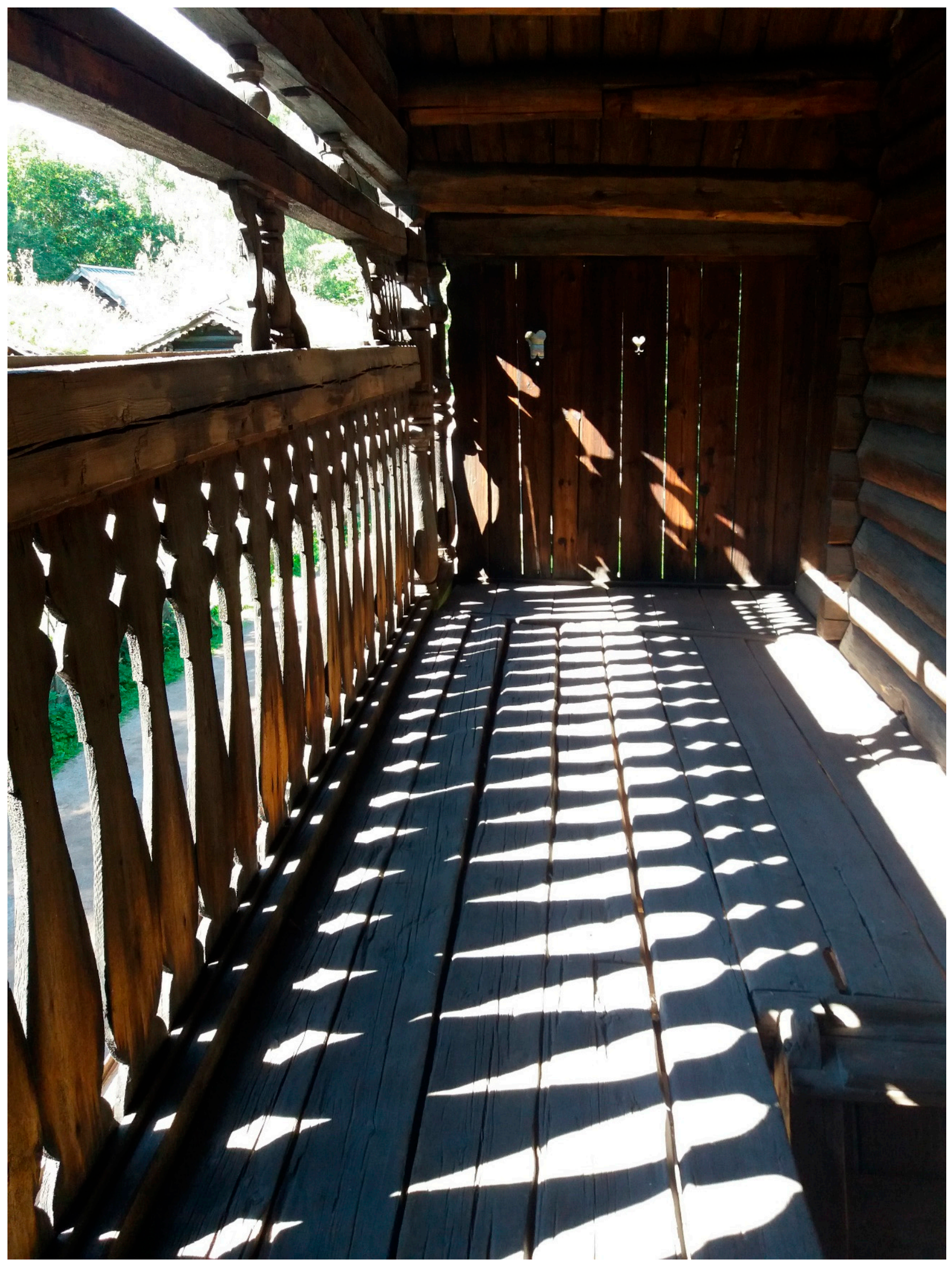

Figure 24. Breathing screen on a svalgang of a store house from Nes in Hallingdal, dated 1700-1797, now in Oslo's Open Air Museum (photo: Raková 2017—published with the permission of Raková). 


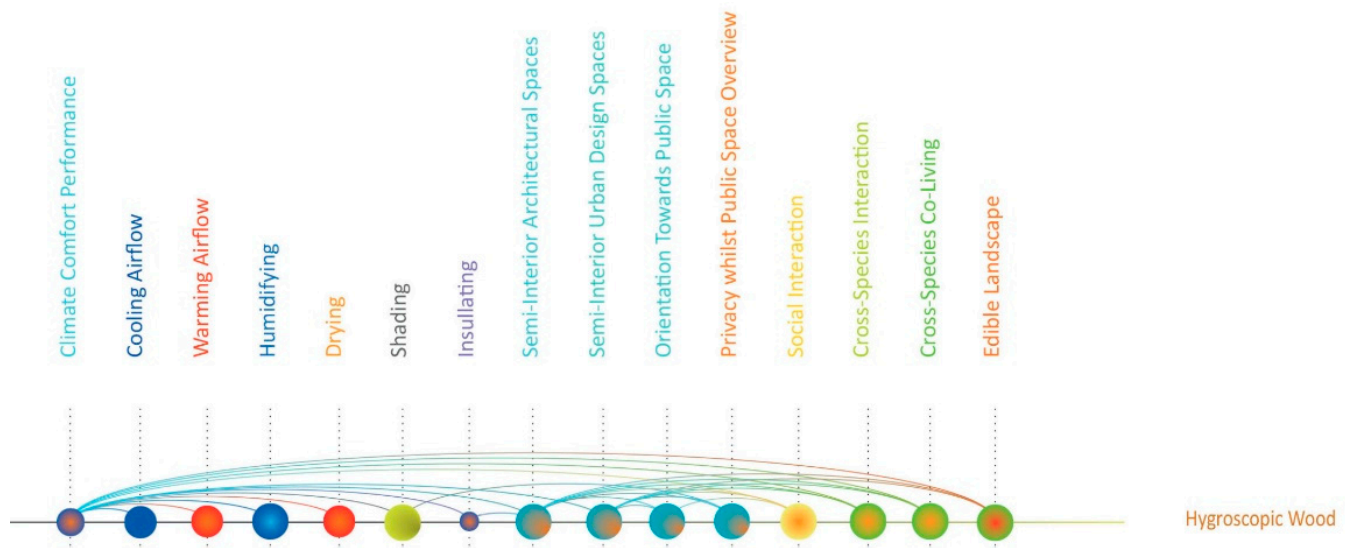

Figure 25. The detail of the gigamap showing ecosystemic performance of the Norwegian breathing screen with hygroscopic properties from Figure 26 (gigamap: Davidová, 2019).

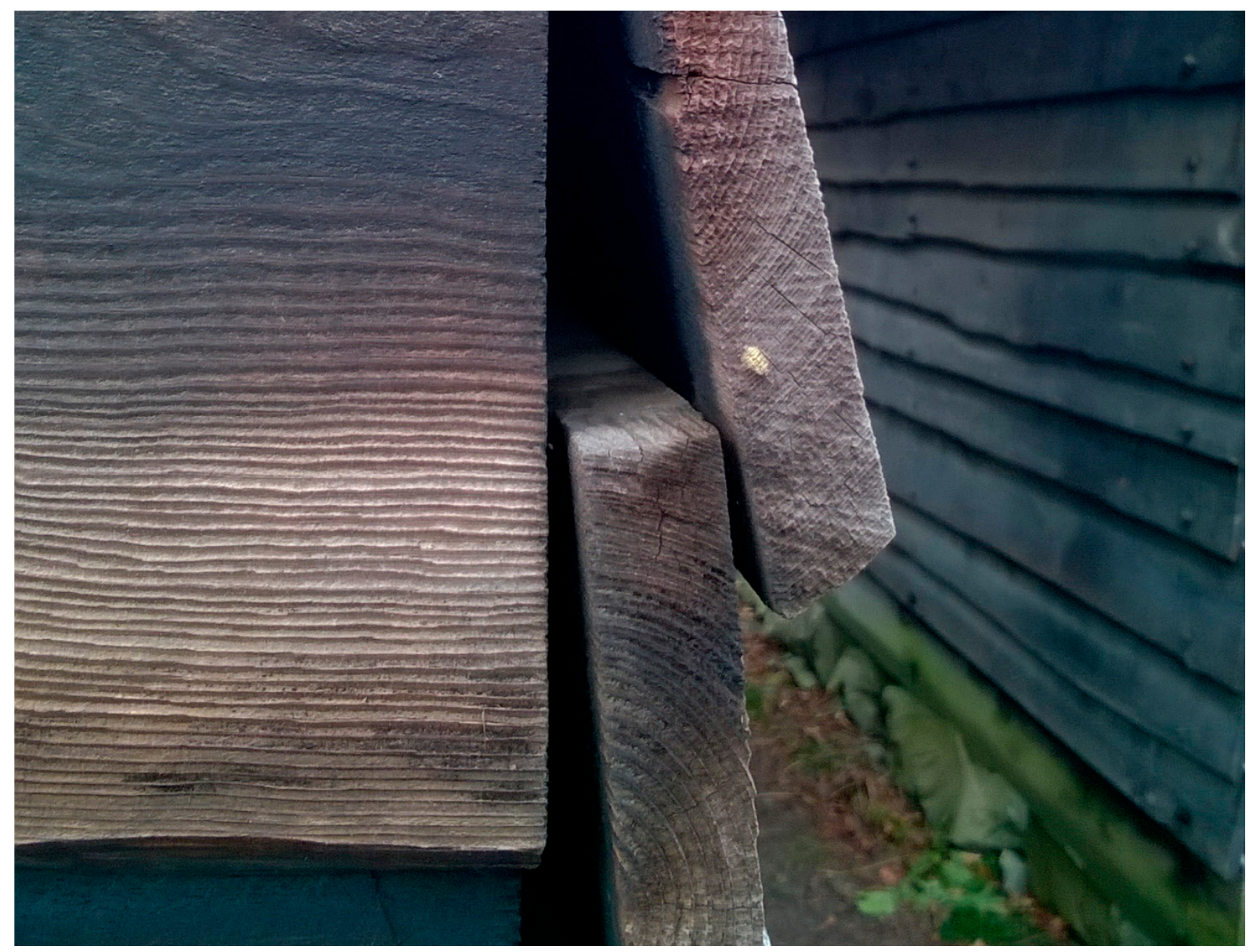

Figure 26. Breathing envelope that uses material performance of warping due to hygroscopicity of a store house from Nes, Øvre Valdsaroy, now in Open Air Museum in Oslo (photo: Davidová, 2016). 


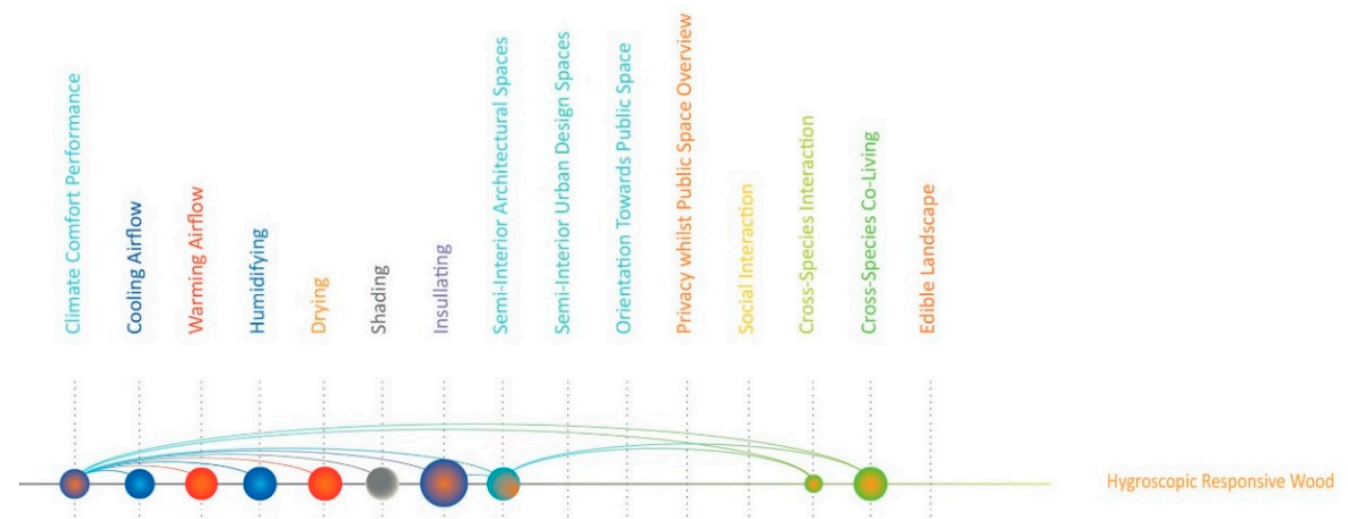

Figure 27. The detail of the gigamap showing ecosystemic performance of the Norwegian breathing envelope with responsive hygroscopic performance from Figure 26 (gigamap: Davidová, 2019).

The first discussed case example is from the subarctic climate of the mountains (see Figure 24). It generates a semi-interior public space and urban design. It offers various opportunities for use by graduating its openings from almost fully open to almost fully closed. It enables rich interactions and opportunities of use even in harsher weather conditions. This svalgang offers many microclimates and opportunities for cross-species interaction and habitation, as it has larger openings in the front and enclosed boundaries on the sides. Therefore, it is suitable for birds and bats nesting, and bees, wasps, and butterflies. Therefore, it also generates edible landscape (honey, pollination, eggs, seeds spread, etc. See gigamap detail in Figure 25). Such performance is critical for the social, cultural, and natural metabolism of the surrounding, otherwise extreme, environment.

The following example is from the oceanic climate of the rainy west coast of Norway (see Figure 26). It envelopes semi-interior spaces for communication and storage and envelopes the main structure of the house at once. Through its hygroscopic responsive properties based on the tangential section of the wood material, it moderates the microclimate and, therefore, generates climate comfort of such in-between spaces. At the same time, such a screen offers interaction and cohabitation with small-sized species such as bees and wasps (see Figure 27) and provides spiritual atmospheres. However, such a traditional envelope does not offer that many opportunities for a variety of uses and social situations. It concentrates on the microclimatic moderation and what modernists would call 'function'. This example is perhaps the closest towards the idea of architectural performance and codesign that is not operated by humans, and this quality shows great potential towards material-environment interaction. However, the screen does not show much other than this property. The following design proposal learns from this 'performance-oriented' [29] school of thought whilst integrating the qualities of the above cases into a more holistic proposal speculated for mild climates.

\section{Synthesis for Today's Application}

Nousala et al. point out that existing bureaucratic systems provide few effective links between decision-makers and sources of real-world knowledge and that they need to maximize the rationality and effectiveness of their decisions. Similar arguments can be made regarding the implementation of administrative decisions in the environment [70]. The governmental adaptation plans are in no way codesigned at the local citizen level, and they typically lack any systemic design or do not include other design professions in their preparatory teams. Applying general (nonlocal-specific) top-down approaches, they are hardly addressing the problematics of real life. However, even nowadays, there is an increase in recent bottom-up vernacular adaptations to today's changing world performed by first-person inhabitants. When possible, people are adding similar bioclimatic layers as discussed in the above section, even in formally temperate climates (see Figure 28). This situation seems to be caused by recent socio-climatic changes around the globe (see Figure 3). 
The aid of codesign on moderating climate and privacy, due to new multidirectional weather extremes and other information-overloaded environments, started substantially changing urban fabrics, legally or illegally, formally, or informally. This situation highlights the potential for investigating the above schools of thought that have evolved in extreme climates over generations, being constantly codesigned and redesigned by first-person vernacular cultures. An interesting step forward would be to engage citizen science in such development, documenting the DIY variations and properties [71]. One possible speculative investigation by design is a responsive screen Ray (see Figure 29).

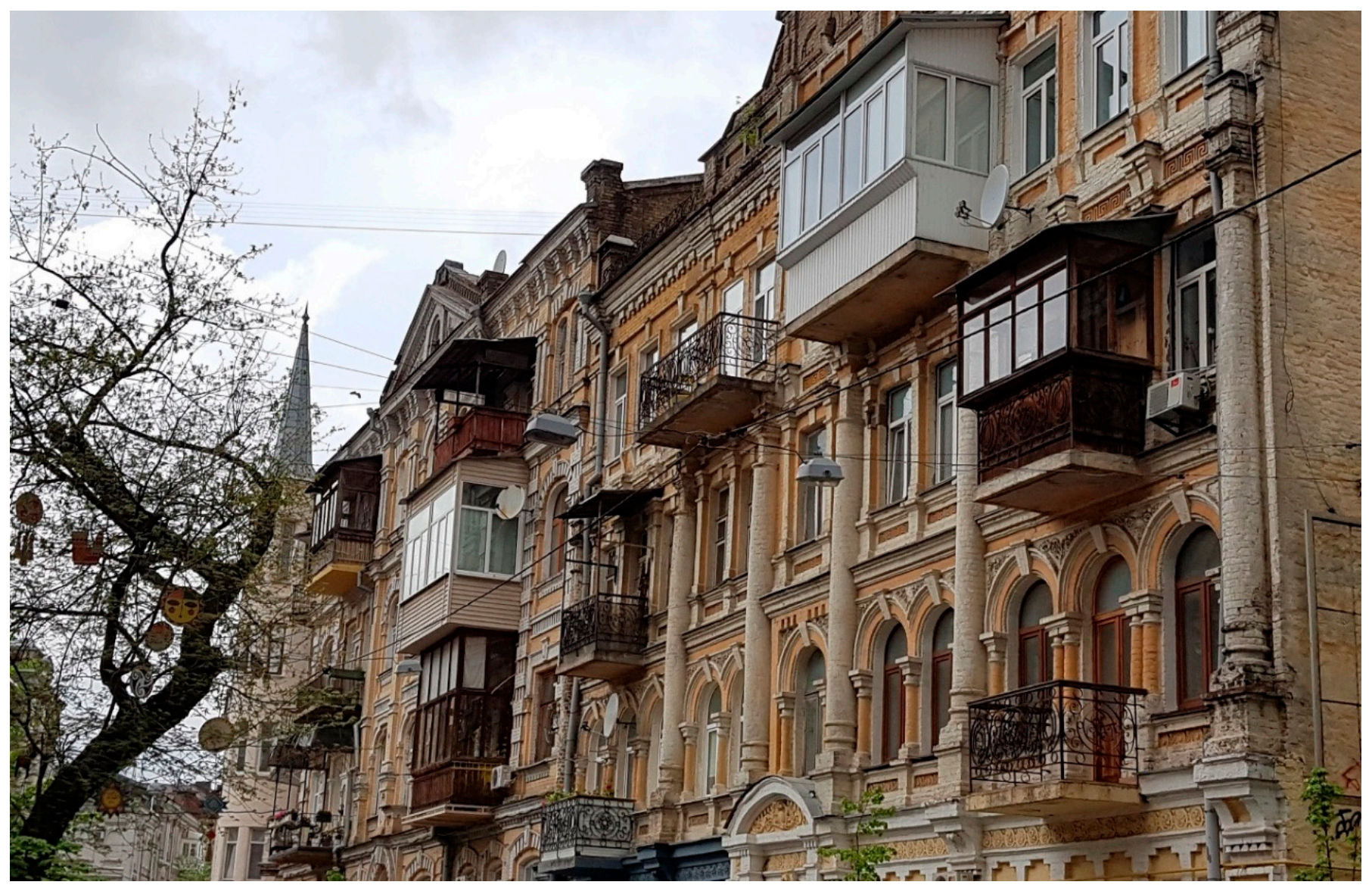

Figure 28. Kyiv, vernacular add-on spaces built on the basis of former balconies (photo: Davidová, 2018).
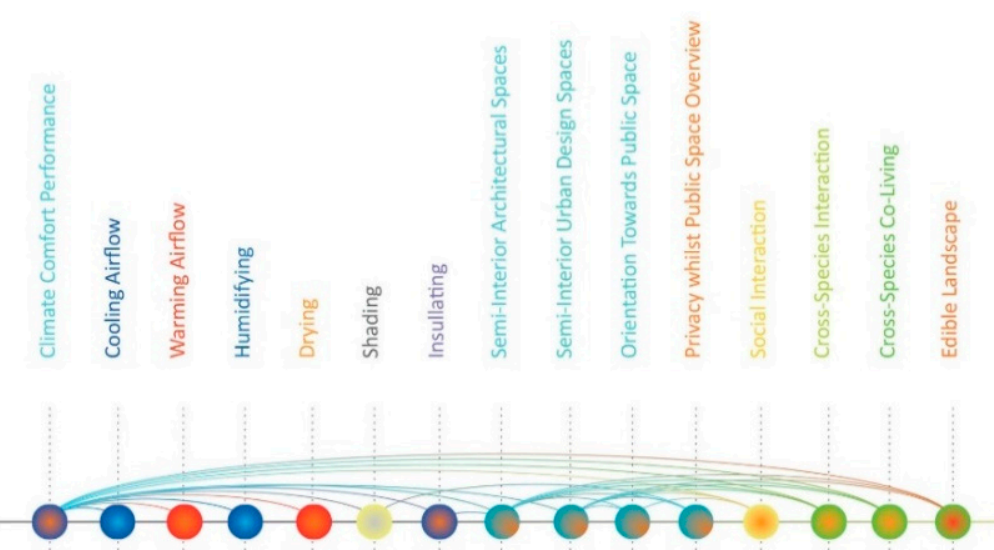

Hygroscopic Responsive Wood and Algae

Figure 29. The detail of the gigamap showing ecosystemic performance of the responsive screen and envelope Ray (gigamap: Davidová, 2019). 
As a synthesis of the schools of thoughts, a climate responsive screen Ray was designed as the bioclimatic layers of the onion peel principle of the built environment and other cultural landscapes (i.e., semi-interior spaces) in mild climates. It can offer cross-species coliving situations as we are currently struggling with climate extremes and biodiversity loss. It learns from and synergises the above-discussed examples of schools of thoughts developed in climates of diverse extremes (low / high temperature, humidity, and precipitation). In today's originally moderate climates, we are experiencing extreme waves of the kind of weather events that have been common in extreme regions for a long time. Equally, we are receiving waves of human and nonhuman refugees from extreme climate locations across different species, cultures, or political situations. This situation occurs because, in many regions, the climate becomes unbearable for its citizens, who have no time to adapt. Therefore, the environmental-socio-cultural needs need to be addressed in the current situation. These items and their conditions are truly interrelated. We need to consider them if we wish to talk about adaptation. Therefore, this article proposes new and parasitic adaptive systems to recent cities and other cultural landscapes. It is not possible to turn down and build our recent world again. However, it is possible to redesign it with systemic interventions, parasitising existing infrastructures, following evolution rather than demolition.

To relate to the above samples (see Figure 29), the author's synthesising Ray screen design performs based on the responsivity of solid wood through the warping of panels in tangential sections such as in the Norwegian screen case (see Figure 26); in addition, it evaporates and circulates the moisture in arid conditions such as in the oriental mashrabiya (see Figure 22). Its openings are substantially larger when warping due to the hot and dry weather. Therefore, they also enable more cross-species opportunities for climate-related use (see Figure 30) and social situations. This performance is even more supported by algae habitation that regulates the moisture content of the wood. The screen performs based on wood warping of the panels cut in tangential sections in dry and hot weather; this is supported by sorption caused by algae habitation that increases its performance. The screen is airing and humidifying the semi-interior space in hot and dry climate and protects it in cold and humid conditions. The Ray screen's climatic moderation supports coliving with other species in the semi-interior and urban design spaces and architectures that it is designed to envelop [3]. The system can be applied to breathable fences, balconies, staircases, workshops and storages, facades, as well as it can be helpful to dwellings of other species such as in the case of the responsive insect hotel, TreeHugger (see Figures 31 and 32) [72]. Such 'artifacts' can stimulate the ecosystemic performance of cities and regions' metabolism. Even the small insect hotel that, due to the variety of climatic qualities, supports the central city's insect biodiversity also serves as a restaurant for bats and birds on the central urban biocorridor. Enveloping larger spaces that are at the building permission stage can create habitats for bats and bids, attracting larger species to feast. The TreeHugger is the only application of the current responsive wood research that deals with habitation, though it is just a small urban intervention for insects. Such application is however scalable to architectural scale and for larger species. 


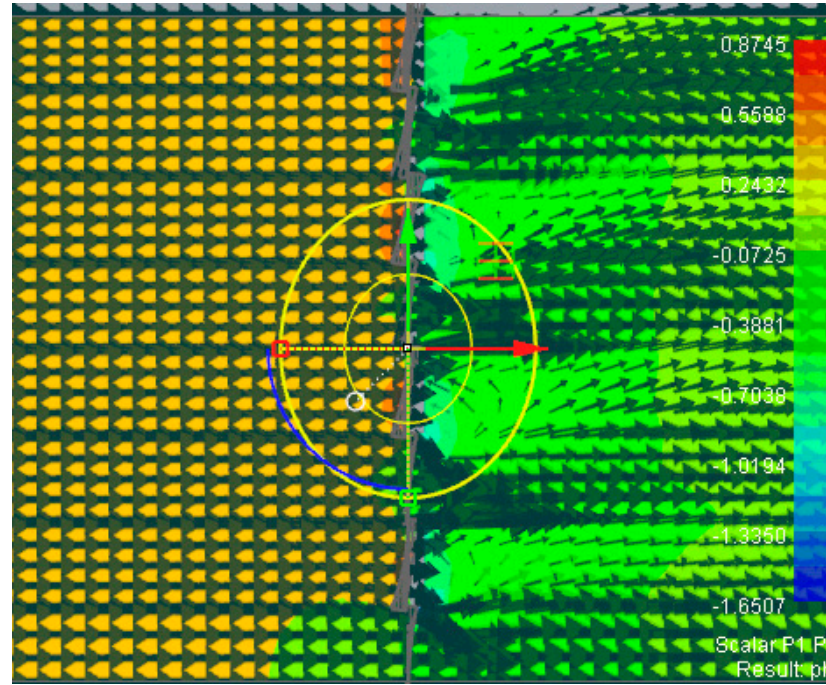

(a)

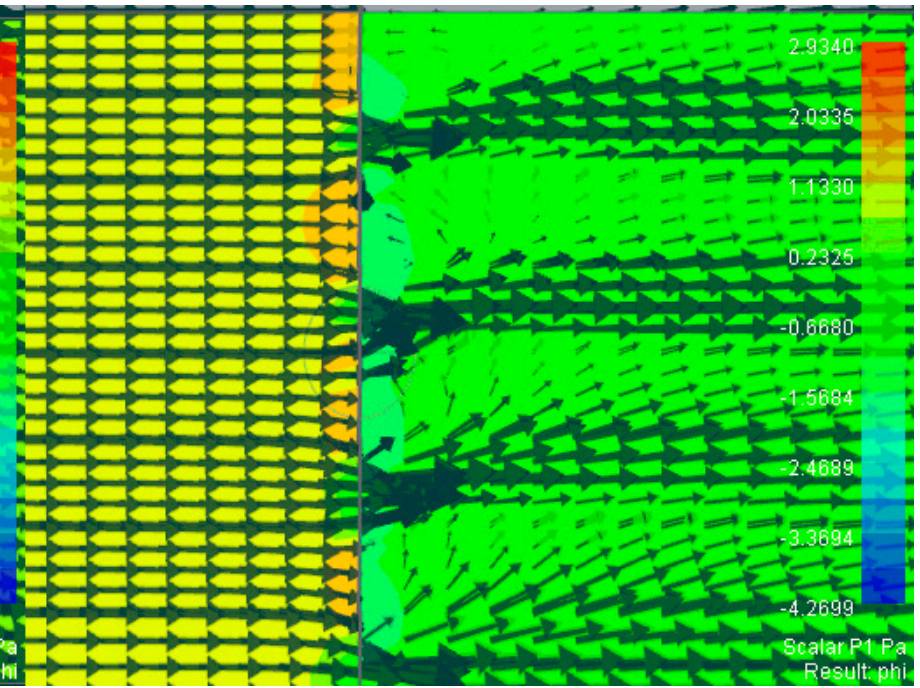

(b)

Figure 30. RhinoCFD fluid dynamics simulations illustrating the exchange between exterior and semi-interior spaces through Ray envelope; from left to right: (a) on the left: situation of dry and hot weather when the screen is open; (b) on the right: The situation with higher humidity and low temperature (simulation: Davidová 2017).

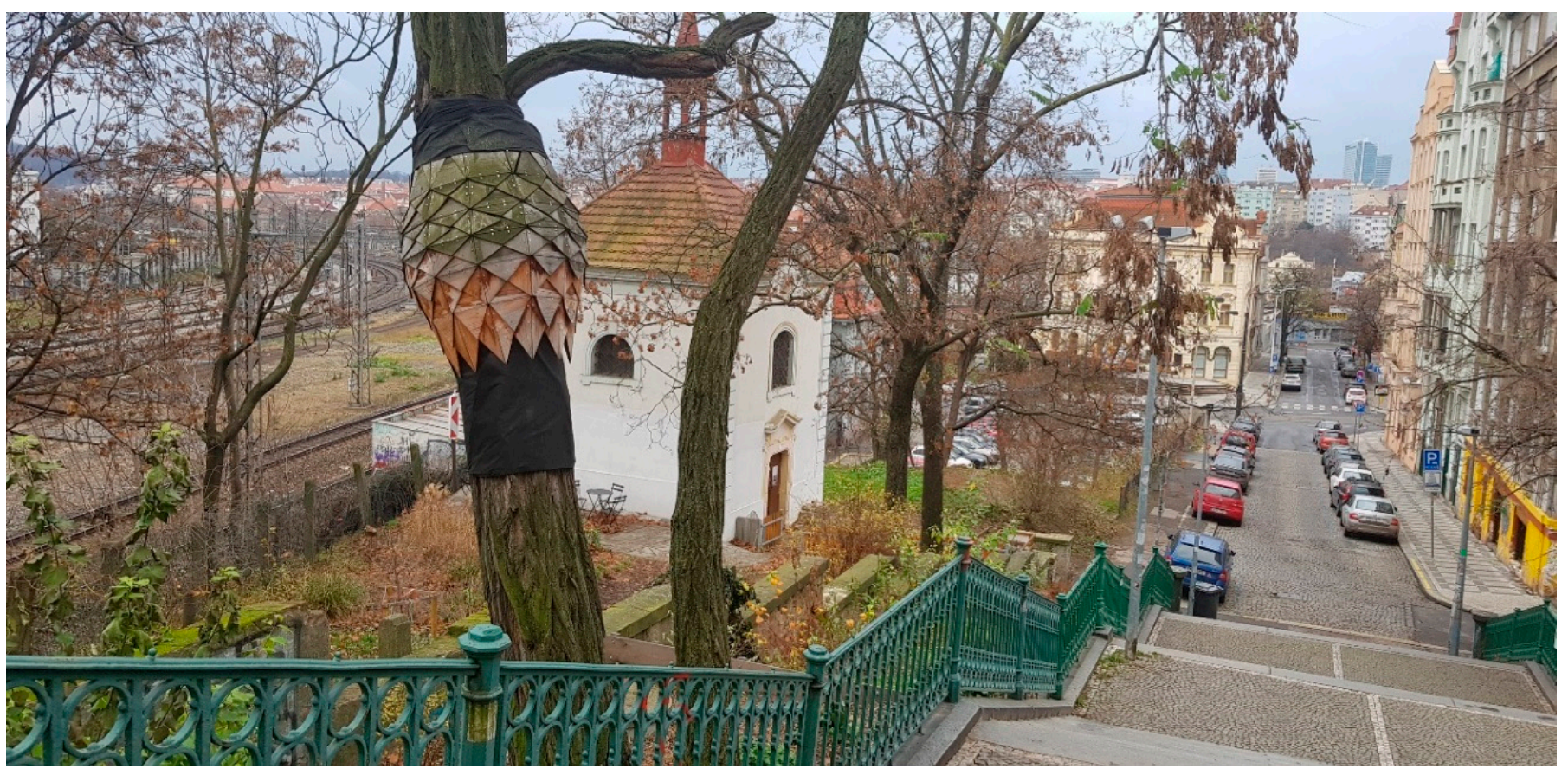

Figure 31. TreeHuggerCZ — responsive wood insect hotel offering habitation to multiple species of insects and algae due to the all-world axis orientation and responsive wood performance. It also supports nutrients for birds and bats (2017, Prague, Czechia) (Photo: Davidová, 2020). 


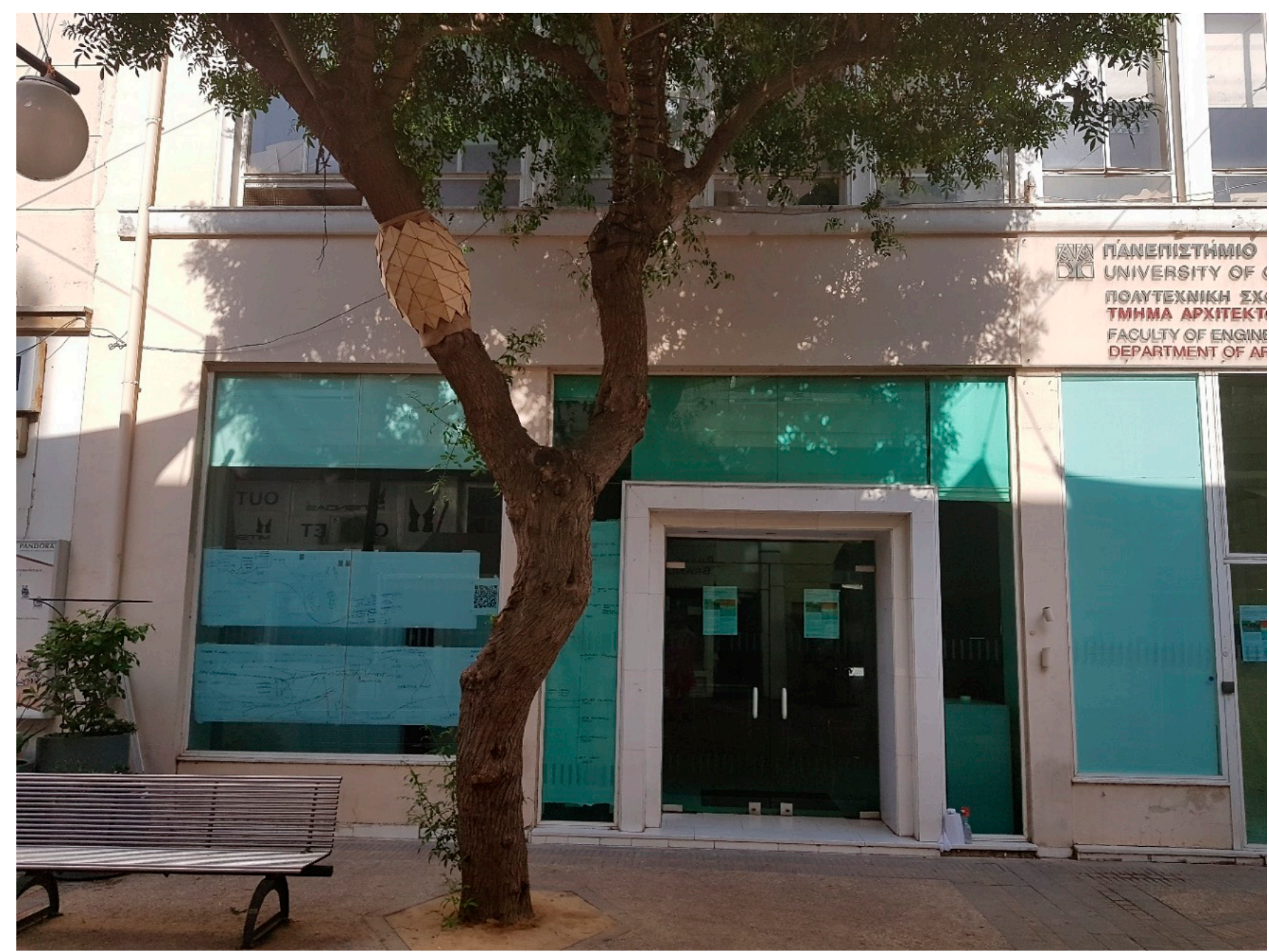

Figure 32. TreeHuggerCY-responsive wood insect hotel offering habitation to multiple species of insects and algae due to the all-world axis orientation and responsive wood performance. It also supports nutrients for birds and bats (2018, Nicosia, Cyprus) (Photo: Davidová, 2018).

\section{The Ray Screen Development}

Though inspired by the research on composite responsive envelopes introduced by Hensel and Menges [60], the screen Ray takes advantage of Norwegian traditional architecture solution by using solid wood. The climatic performance of such solution was discussed by Larsen and Marstein. The panels open in dry and hot weather, allowing the air inside, whilst they close in high humidity and low temperature [73]. This is caused by hygroscopicity of solid wood cut in tangential sections where the fibre density on the left and right side of the panel are different. The challenge of the responsive solid wood from traditional Norwegian architecture is that the responsiveness is too low for generating social performance, cross-species habitation opportunities, and attractive light conditions and atmospheres. This was investigated through designing. The first design concepts 'Sponge' (see Figure 33) and 'Ray 1' (see Figure 34) were simulated in Grasshopper for Rhino 5 based on the responsiveness measurements performed on wooden pine samples. 


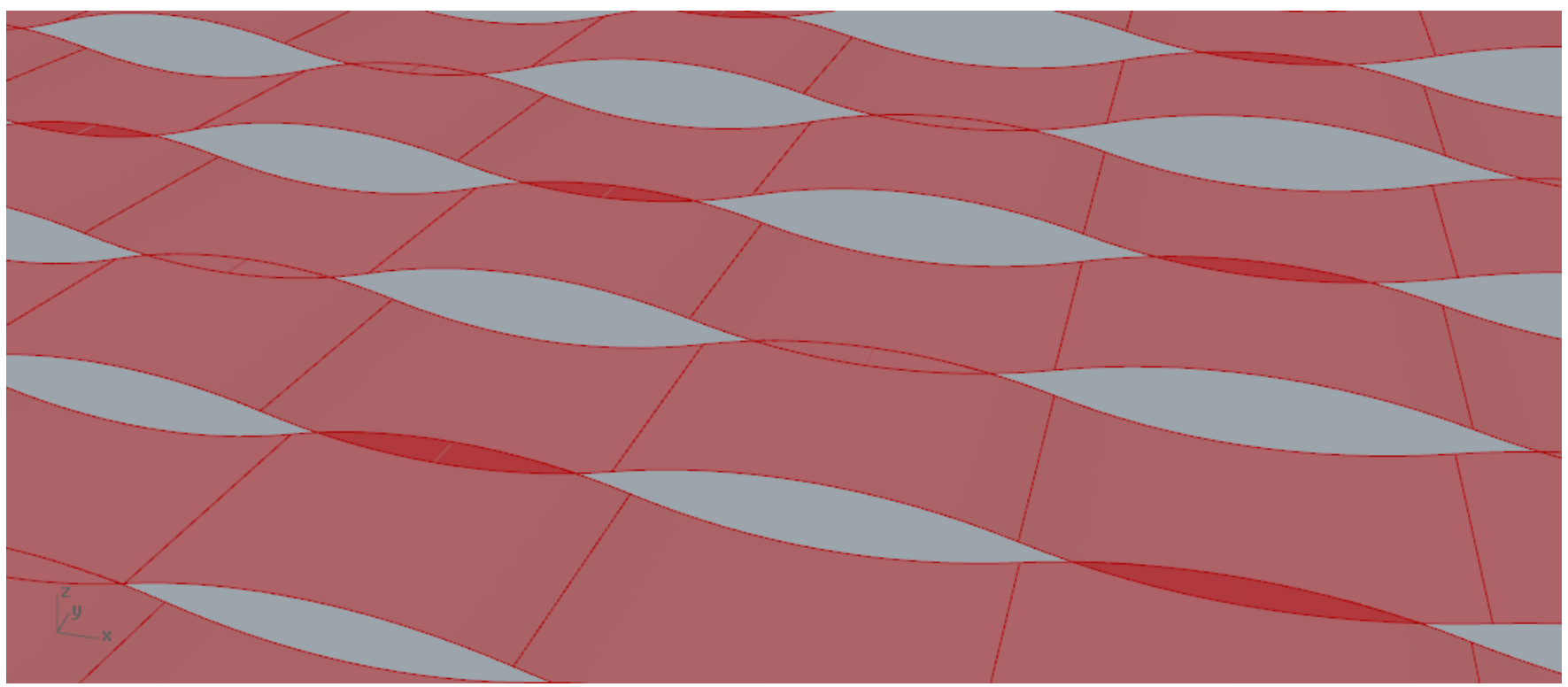

Figure 33. Concept Sponge parametric model (Davidová 2013).

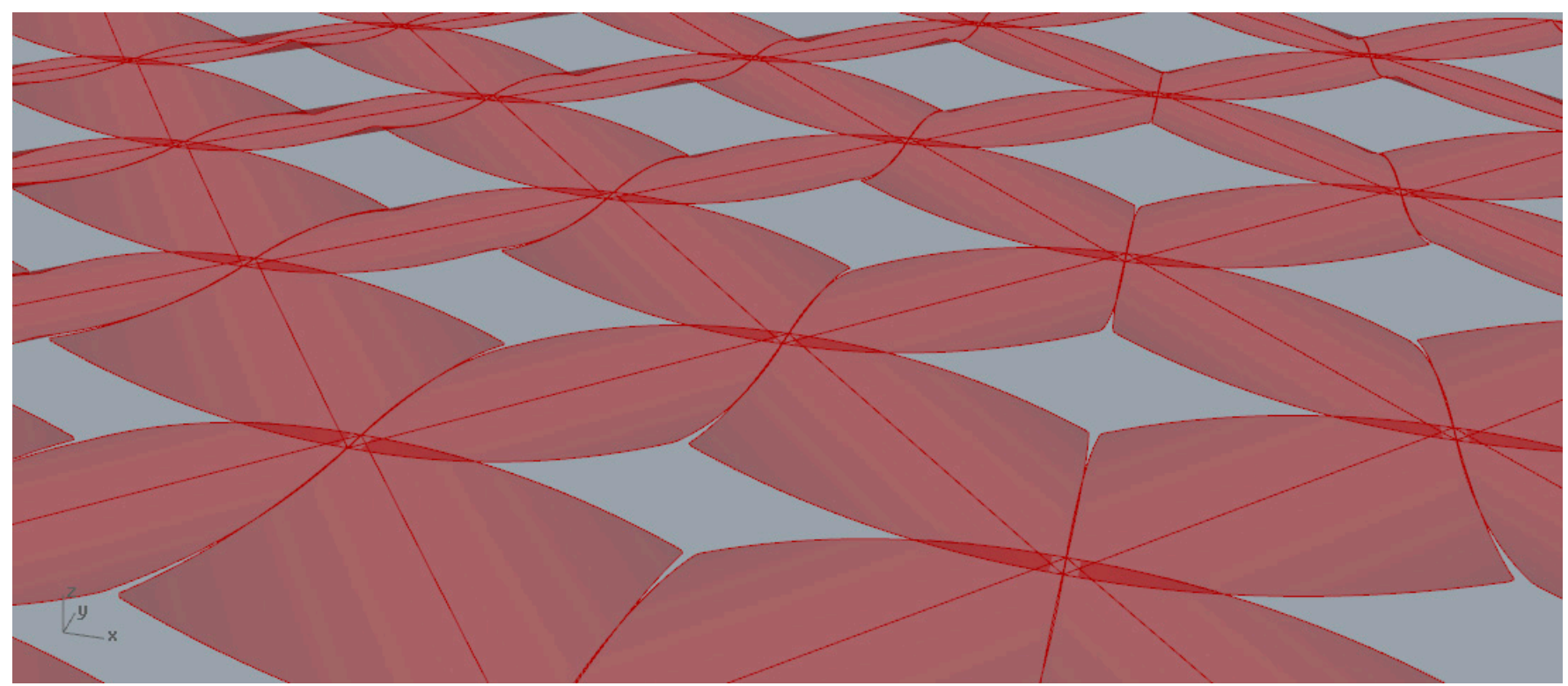

Figure 34. Concept Ray 1 parametric model (Davidová, 2013).

\subsection{System Sponge}

The system Sponge has its advantage in the resistance to sudden rain. Its disadvantage is the interdependency of each plate, as the wood does not shrink in exactly the same way. Another problem is that the system shrinks in general. With $30 \mathrm{~cm}$ plates, the system shrinks by ca. $3 \mathrm{~cm}$ with 7 panels. For the height, the system extends $28 \mathrm{~cm}$ with eight panels of $20 \mathrm{~cm}$ height with a $3 \mathrm{~cm}$ overlap. This could be developed into a nondependent system, but the durability would be questioned anyway as the plates would move against each other. It was simulated that the concept generates $1 \mathrm{~cm}^{2}$ airing gap per $10 \mathrm{~cm}^{2}$ of the surface in $10 \% \mathrm{RH}$ and $21^{\circ} \mathrm{C}$. 


\subsection{System Ray}

Concept Ray 1 was not resistant to sudden rain, while its performance was much better. According to the simulation for $10 \% \mathrm{RH}$ and $21{ }^{\circ} \mathrm{C}$, it generates $1 \mathrm{~cm}^{2}$ airing gap per $7.2 \mathrm{~cm}^{2}$ of the surface area because of the use of the triangles that warp more than the rectangles. The system had overlapping from the lower parts of the boards and not from the sides. The system was further developed into prototype Ray 2 (see Figures 35-37) which dealt with the material properties of wood directly with the capacity of different warping based on the position of the tangential cut within the tree trunk, thus allowing overlapping by layering.

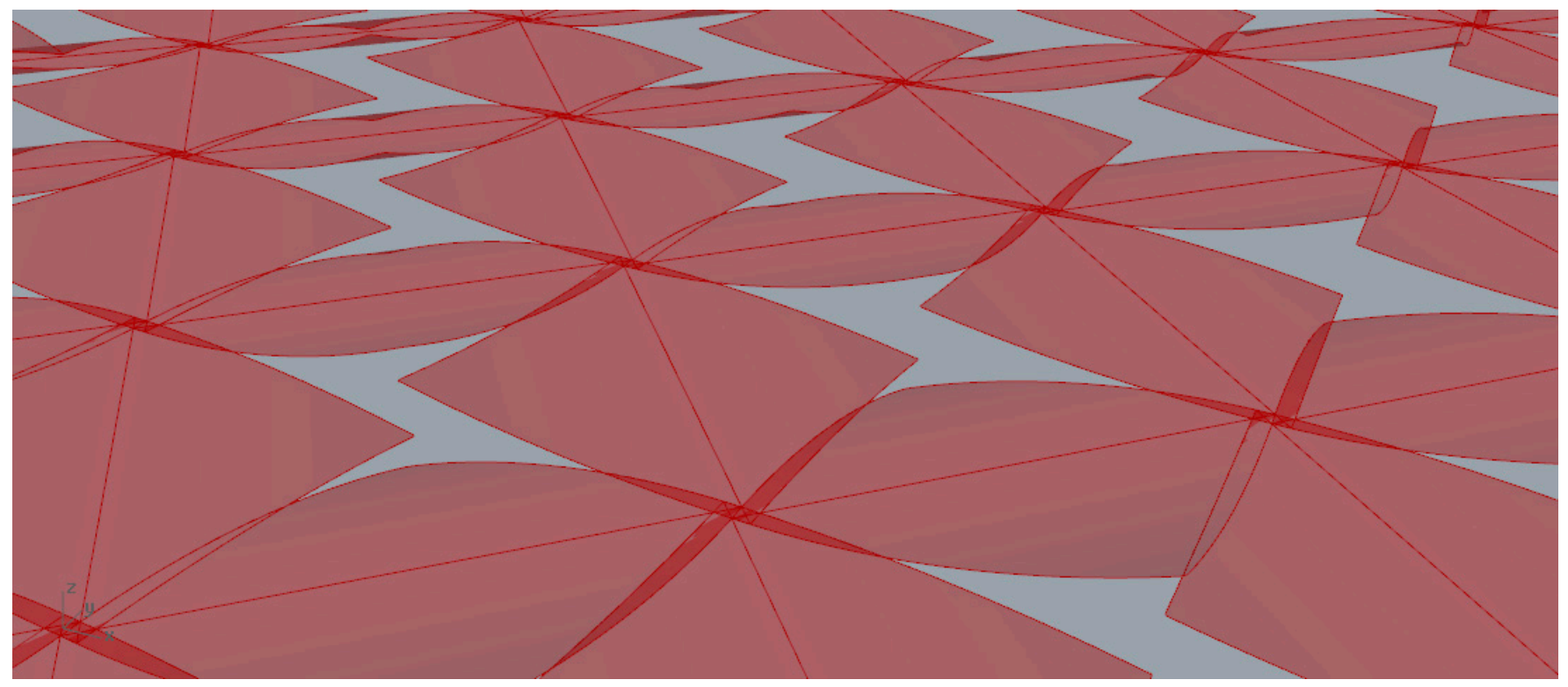

Figure 35. Concept Ray 2 parametric model (Davidová, 2013).

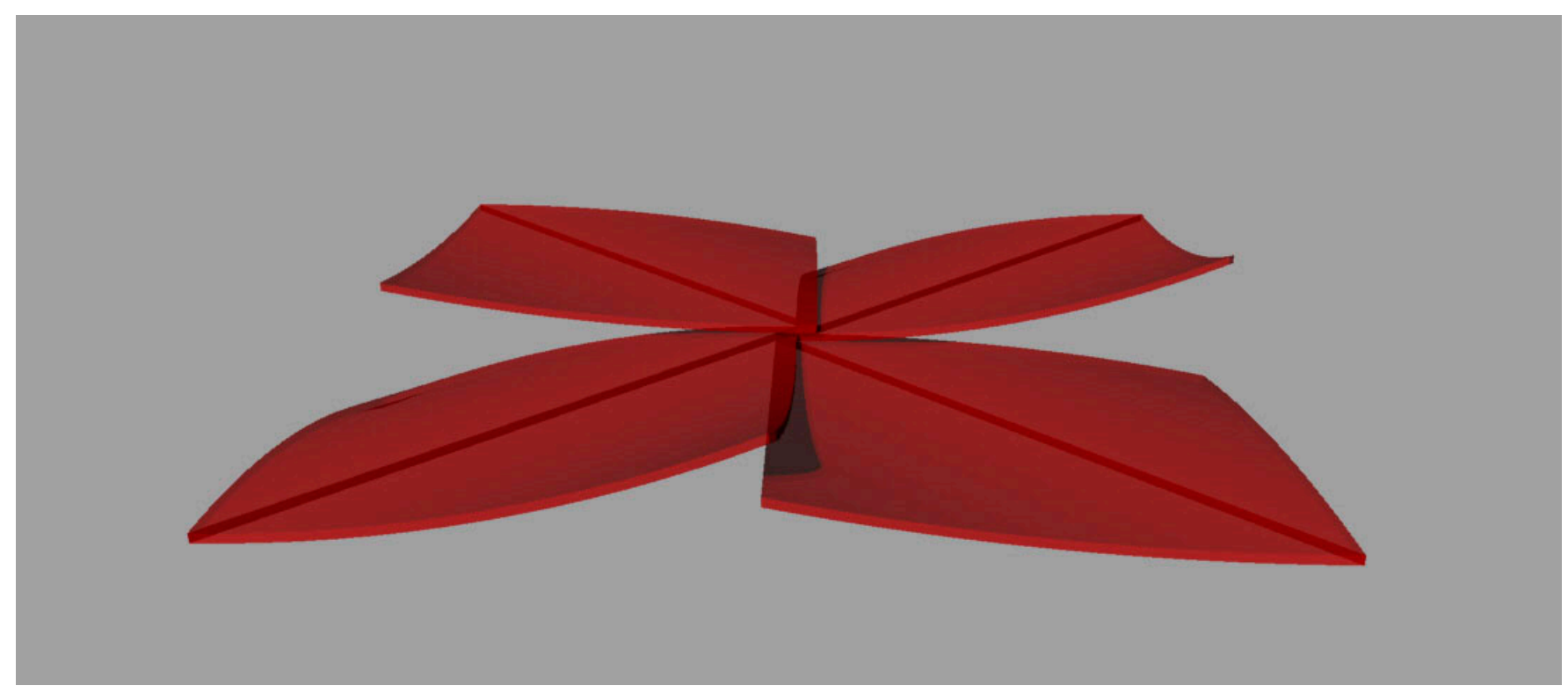

Figure 36. System Ray 2 layering (Davidová, 2013). 


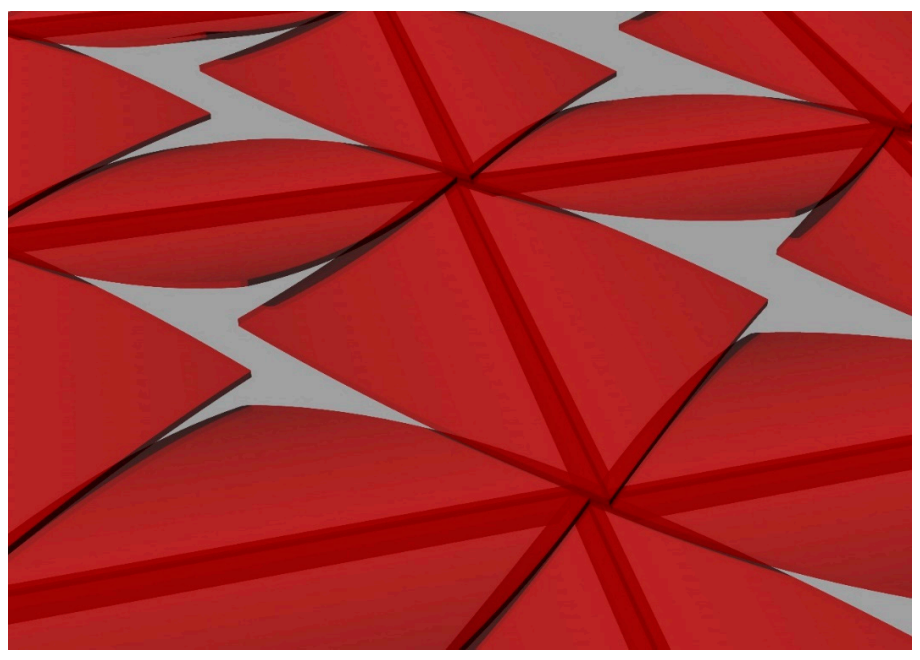

Figure 37. System Ray 2 model of the prototype (Davidová, 2013).

Ray 2 was developed from the concept of Ray 1 but adding resistance to sudden rain. Based on the properties of tangential cuts from different positions of the tree trunk, the plates are combined in diagonal directions. In $10 \% \mathrm{RH}$ and $21^{\circ} \mathrm{C}$, the concept generates $1 \mathrm{~cm}^{2}$ airing gap per $7.8 \mathrm{~cm}^{2}$ of the surface area which is good enough for planed performance. This fact was first simulated in Grasshopper for Rhino 5 based on measured samples and afterwards measured on the prototype. This performance was increased by algae growth on the prototype's surface (see Figure 38). The system Ray 2 is based on two triangles fitted together into a rectangular shape while each of them has a different orientation of the tangential section. The upper one warps outwards and the lower one inwards, generating a large gap within the system for airing. Within the grid, based on two diagonals, one direction is based on the rectangles coming out from the centre of the tree trunk and the other direction from the border pieces. The direction of the boards that warp more (the one from the centre of the tree trunk) is in one plane. In the other direction, the board is fitted under the layer of the first direction at its top while fixed on the top of the first direction at its bottom. This ensures that the boards overlap within the whole system and therefore offer protection from the sudden rain when the system does not react immediately.

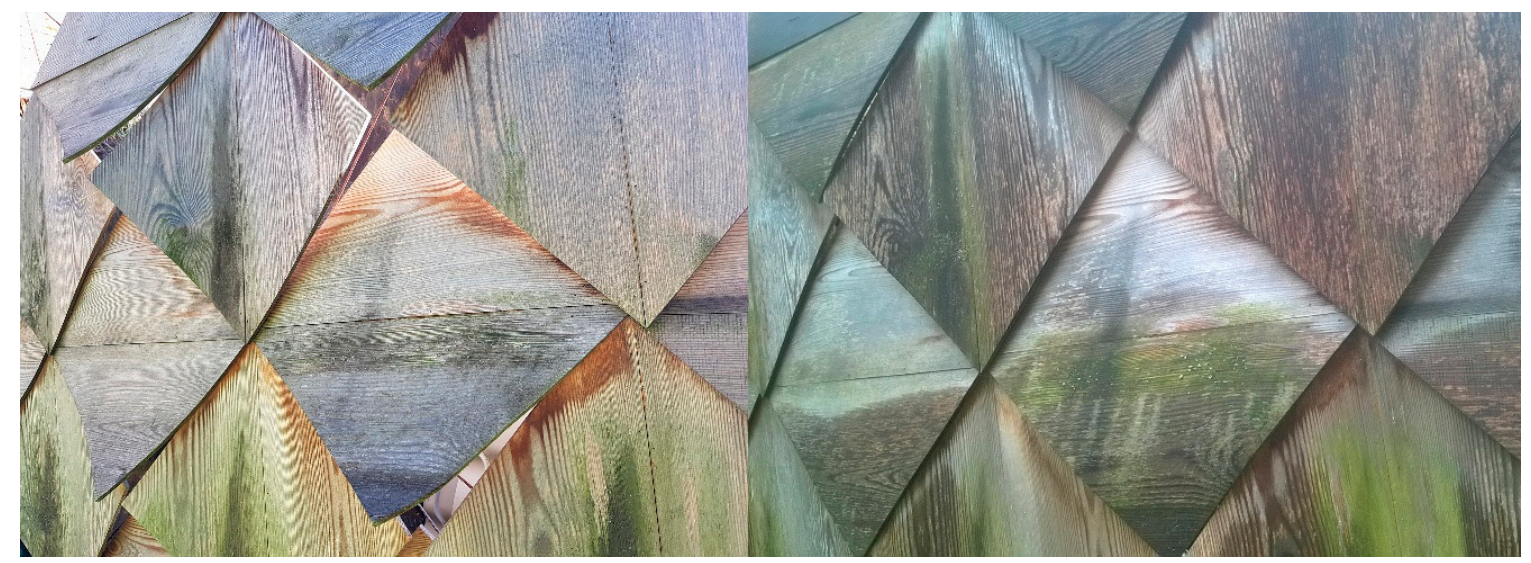

(a)

(b)

Figure 38. Ray 2 prototype from left to right: (a) in semi-dry June 2018 weather when the screen is open for boundary exchanges between exterior and semi-interior; (b) after light rain in April 2017 when the system is closed, which does not allow the humid or cold air to pass through the boundary, after five and four years, respectively, of exposure to weather and biotic conditions (Photos: Davidová, 2017-2018). 
To protect the prototype from decaying species the wood for prototype Ray 3 (see Figure 39) was soaked in salt water to wash out sugar and amyl [74]. The prototype closes its panels at $75 \%$ relative humidity level and is also treated by salt water against biological decay and fastened by plugs attached at lower moisture content to the construction frame. The glass-bubble-based thermal comfort solution originated from NASA technologies and performing on reflection, was selected instead of any kind of thermal insulation [5].

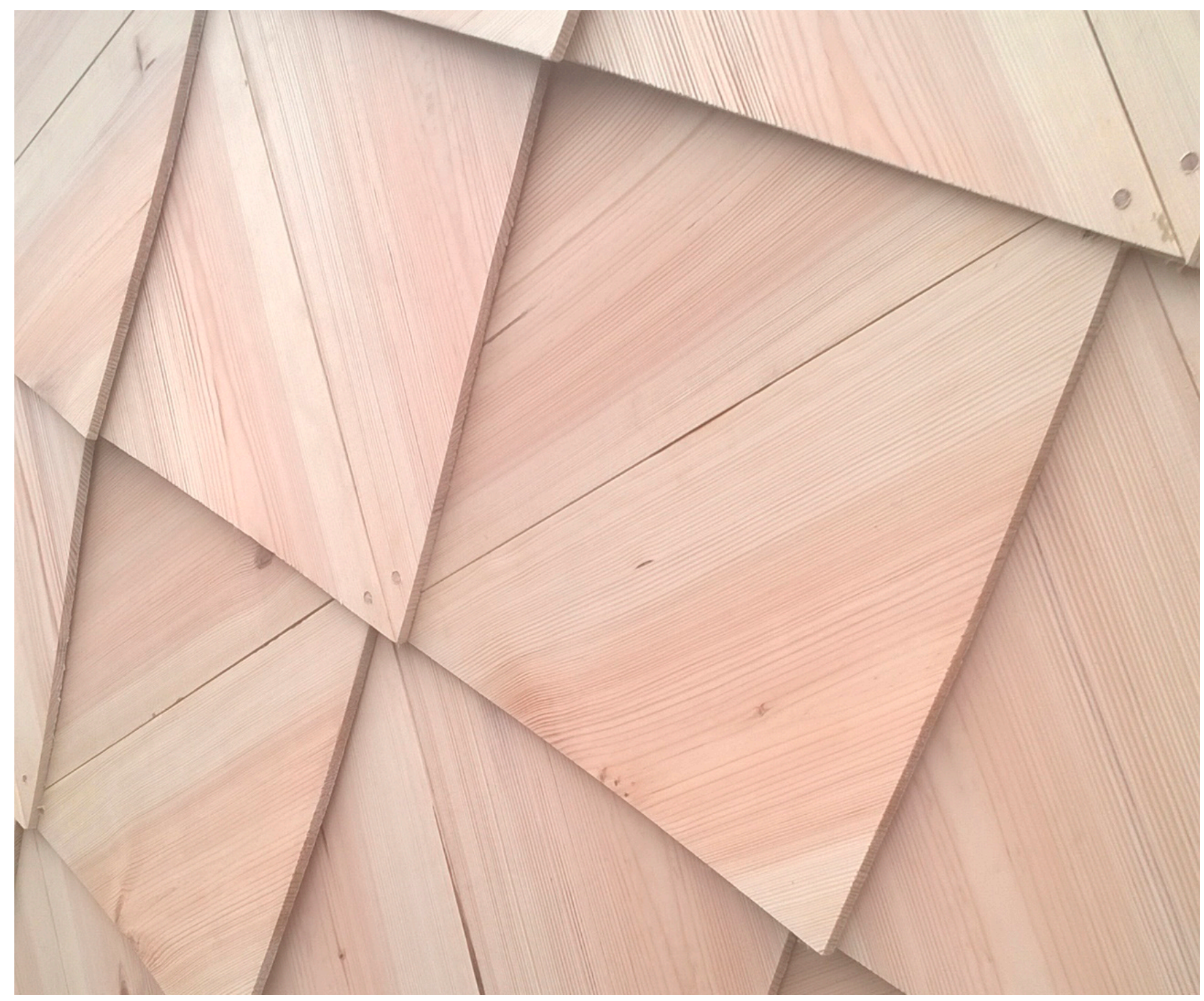

Figure 39. Ray 3-Prototype (Photo: Davidová 2016).

\section{Discussion and Conclusions}

Morin explains that society is the product of interactions between human individuals, but also that society is constituted of its emergencies, its culture, and its language, which retroact to the individuals and thus produce them as individuals supplying them with language and culture. We are products and producers [75]. The same could be said about multi-species culture. This research shows that there could be different layers to these interactions generated through culture, and the culture is generated through them equally, being the products and producers. Similarly, it goes in this case with an environment that, of course, also integrates culture. The inclusiveness of culture within the environment and culture's relationship to it was avoided through modernism, which tried to both control and program through alienated engineering, e.g., avoiding birds nesting on the building 
facades. This alienated engineering has been restricting any relations to life in opposition to what has been present in indigenous and vernacular cultures. Therefore, this modernist approach (there are of course several exceptions) has never received acceptance through real life, ignoring its complexity, beauty, and togetherness. Many species have recently been searching for habitats in the built environment as agricultural land became poisoned by pesticides, herbicides, etc. Wild birds are nesting on human balconies or windows' flowerpots; hedgehogs, frogs, and foxes live in central urban front and back gardens. What used to be seen as a weakness is now hugely appreciated by local communities. These largely participate in citizen science, adapting semi-interior or exterior parts of their homes to offer foodscapes and habitats with support of industrial birdhouses, insect hotels, hedgehogs houses, frog pools, bird feeders, pollinators' gardens, etc. (e.g., RSBP or Woodland Trust products). This evolution of culture needs to be reflected in relevant policies and adaptations in urban and peri-urban environments.

Morin also clarifies that in opposition to reduction, complexity requires that one tries to comprehend the relations between the whole and the parts. The knowledge of the parts is not enough; the knowledge of the whole as a whole is not enough. If one ignores its parts, one is thus brought to go back and forth in a loop to gather the knowledge of the whole and its parts [75]. Therefore, we must consider urban metabolism when discussing even small artifacts. Complex adaptive systems theory seeks to discover common principles of the organization across social and material categories, and it is apparent that the environmental crisis also produces social crises [76]. Social and environmental justice are closely related [77-79]. Moreover, cultural justice should not be neglected as it is a critical actor of socio-environmental relations. These are frequently feedback looping between collective and individual and across different scales. Moreover, Capra explores notions like spirituality that is usually understood as a way of being that flows from a certain profound experience of reality known as 'mystical', 'religious', or 'spiritual' experience. He points out that there are numerous descriptions of such experience in the literature of the world's religions, which tend to agree that it is a direct, nonintellectual experience of reality with some fundamental characteristics that are independent of cultural and historical contexts [80]. At this point, the tacit knowledge is crucial. Furthermore, the link between humans and nonhumans may be intrinsically mysterious [81]. Species typically relate to emotional connections amongst them, next to the symbiotic, positive, or negative connections. Jagodzinski states that to approach the inhuman in us suggests an infinity between plants (vegetal), animals and the human-the homology between the act of reading a text and the reading of animal tracks by indigenous ancestors or the many homologies between the human and animal aesthetics, not to mention the range of gestural and linguistic capacity of chimpanzees, dolphins, and whales. When it comes to skin, the inhuman is foremost extended to the vegetal [12]. Such discussion makes clear that there is a need of relating hard with soft; or even tacit data and knowledge and that such relations need to be investigated. This can be related and speculated upon through research by design that is employing visual gigamapping in combination with full-scale prototyping. The feedback loops between investigated schools of thoughts synchronised with first-person investigators' memories of atmospheres and the first-person design prototypical speculations help develop holistic design. Such holistic design needs to synergise the environmental, social, and cultural with the material.

Both the southern and the northern breathing walls are moderating the interaction of the building with extreme climate and its environmental-sociocultural and material interactions [58]. The social is not limited purely to humans [82]. Therefore, this research is integrating the coperformance of living and nonliving entities in the sense of Margulis' understanding of life [83]. A new complexity to conceive a living organization emerges: autonomy cannot be conceived without its ecology [75]. That autonomy is drastically moving with climate change and cross-species and cross-cultural migration. This migration includes the human species, amongst others. Gehl states that the interplay between the intensity and distance of sensual impressions is widely used in human (and other species) 
communication. The intense emotional contacts take place at relatively close range, 0 to $1 / 2 \mathrm{~m}$ ( 0 to $2 \mathrm{ft}$.), where all the senses can work together and where all nuances and details can be perceived clearly, while the less intense contacts take place at greater distances, $1 / 2$ to $7 \mathrm{~m}$ (2 to $20 \mathrm{ft}$.) [66]. However, this can vary for different cultures, landscapes, territories (and species). Moreover, a similar relation in reference to microclimate appears in individual and collective climate comforts that relate to behavioural comforts. With recent climate extremes and enhanced social interaction comfort, we need to moderate climate and provide coliving opportunities in milder regions the same way as it has been a tradition in vernacular cultures in extreme climates. The moderation needs to learn from a variety of extreme peaking examples as we have recently been experiencing a variety of extremes (droughts, floods, extreme heat, or cold waves).

Spotswood et al., in their review, pointed out that several species benefit more from urban settings than from other environments. This may be attributed to the few adaptations necessary for their survival [65]. Urban spaces are to become the stage for conditions to be specialised for nature and for producing food that is fit for the future, as well as becoming areas in which to experiment, by staging and testing out solutions to contemporary environmental, climate, and structural crises [84]. The provision of coliving opportunities with insects that are seen as an advantage in this article with respect to recent biodiversity loss is, however, criticised in different, still very modernist, vernacular architectures' knowledge adaptations strategies by recent authors such as, e.g., Shritastav and Jones [85]. This fact is particularly surprising as the same authors call for a greenery integration within the same context (ibid), obviously not considering at least any habitation of pollinators within a coperforming ecosystem. Therefore, with recent progression hope, climate change cannot be handled any other way than by social change. This social change that necessarily integrates and synergises with other changes is envisioned by the author as a transition towards the post-Anthropocene of cross-species coliving within the biotechnological landscape and biosphere. This research by design speculates that connectivity and boundaries are equally important in the landscape. However, as we cannot have full connectivity, similarly, we cannot have unpenetrable boundaries to motivate both transition and habitation of species. Therefore an 'artifact' of breathable urban device can generate ecosystemic change on a broader scale, if it is integrated with social change.

Following the multiplicity of diverse theories and visions integrated into a complex picture, this article and the research by design work touch the synergies of the collected and generated holistic knowledge for former design interpretations and new design generations. The two kinds oscillate in feedback loops in a nonlinear manner in time and across various disciplines. Ehrenfeld points out that we live within institutions based on flawed beliefs and norms - flaws that can be traced to the way we hold reality. The persistence of these ideas can be attributed to the strongly conservative nature of societal reproduction and the lack of any serious intellectual revolt in the West [86]. He has argued that the Earth system would produce sweeter fruit if those two ideas were replaced with (1) the cosmos as a complex system, and (2) the human being as a caring creature [87]. This article discusses such possible ecosystemic change, and therefore also the change in governance and social systems, within the urban and semi-urban fabric and metabolism that may lead towards climate change adaptation and biodiversity loss mitigation, whilst supporting food security, climate and social comfort, and urban connectivity across multiple species, as well as their appearance and abundance. This situation can be achieved through either newly built architectures and urban design or parasitic structures, nested on current build-up environment as a sort of interpretation of 'auxiliary architectures' [88] while inventing schools of thought through vernacular culture codesigned coperformance. Unfortunately, with current economic models, the price is guaranteed by climatized square meters of the buildings [5]. It will be interesting to see how this will be affected by the recent COVID crisis when people started to seek nature and more outdoor or semi-interior spaces. The discussed, often parasitic, structures can serve as built environment 'systemic interventions' 
and 'leverage points' [24] transitioning towards systemic adaptation to a possible postAnthropocene era on a coperforming biosphere, the 'Gaia' [89].

\section{Patents}

The screen Ray was patented by Industrial Property Office in Prague in the Czech Republic [90].

Author Contributions: All authors have read and agreed to the published version of the manuscript.

Funding: The research published in this article is supported by the Deutsche Forschungsgemeinschaft (DFG, German Research Foundation) under Germany's Excellence Strategy-EXC 2120/1-390831618. The authors cordially thank the DFG.

Institutional Review Board Statement: Not applicable.

Informed Consent Statement: Not applicable.

Data Availability Statement: Not applicable.

Acknowledgments: This is an extended paper from the Relating Systems Thinking and Design 8 symposium, held at the Illinois Institute of Technology, Chicago [1]. The study journeys documentation was collected thanks to EEA and Norway Grants, Czech Ministry of Education, Czech Ministry of Culture, Visegrad Funds and LundHagem Arkitekter study trip. The TreeHuggerCZ project was kindly supported by Via Foundation, the Forests of the Czech Republic, Stora Enso, Rothoblaas, Škuta Design and the Faculty of Forestry and Wood Sciences at the Czech University of Life Sciences in Prague and the Czech Ministry of Education. The TreeHuggerCY project was kindly supported by the Czech Ministry of Culture. TreeHuggerCZ Collaboration: Authors: Marie Davidová, Šimon Prokop, Kateřina Zímová, Ondřej Michálek, Kateřina Horák Goryczka, Krištof Hanzlík, Kamil Trgala, Eliška Oberhofnerová, and the Local Biotic and Abiotic Community of Prague 2 District (Co-Design). TreeHuggerCY - eCAADe RIS at the University of Cyprus Workshop: Workshop Tutors: Marie Davidová and Šimon Prokop. 6th eCAADe RIS Organisation: Odysseas Kontovourkis. Site analysis for tree pre-selection and permission negotiation: Panagiota Konatzii and Michalis Psaras. Prototyping workshop participants: Panagiota Konatzii, Michalis Psaras, Stefanos Kyprianou, Marko Vucic, and the Local Biotic and Abiotic Community of Nicosia Centre (Co-Design).

Conflicts of Interest: The author declares no conflict of interest.

\section{References}

1. Davidová, M. Breathing Walls, Envelopes and Screens for Cross-Species Co-Living Adaptation of Built Environment: The Bio-Climatic Layers in Systemic Approach to Architectural Performance. In Proceedings of the Relating Systems Thinking and Design (RSD8) 2019 Symposium, Chicago, IL, USA, 13-15 October 2019; Jones, P., Ed.; Systemic Design Association: Chicago, IL, USA, 2019; pp. 1-24.

2. Davidová, M. Wood's Material Performance: Ray 2. In Proceedings of the Wooden Architecture, Tradition, Heritage, Present, Future, Gdansk, Poland, October 2014; Cielatkowska, R., Jankovska, D., Eds.; Wydział Architektury Politechniki Gdańskiej za zgoda Dziekana: Gdansk, Poland, 2014; pp. 93-99.

3. Davidová, M. Co-Habited, Co-Lived, Co-Designed and Co-Created Eco-Systemic Responsiveness in Systemic Approach to Architectural Performance: A Case Study on Interaction of Performative Solid Wood Envelope Ray and Algae. In KINE[SIS]TEM From Nature to Architectural Matter; João de Oliveira, M., Crespo Osório, F., Eds.; DINÂMIA'CET-IUL ISCTE-Instituto Universitário de Lisboa: Lisbon, Portugal, 2017; pp. 36-45.

4. Davidová, M. Ray 2: The Material Performance of a Solid Wood Based Screen. In Proceedings of the 32nd eCAADe Conference, Newcastle-upon-Tyne, UK, 10-12 September 2014; Thompson, E., Ed.; Faculty of Engineering and Environment, Newcastle upon Tyne: Newcastle upon Tyne, UK, 2014; Volume 2, pp. 153-158.

5. Davidová, M. Ray 3: The Performative Envelope. In Proceedings of the 2016 DCA European Conference Inclusiveness Design, Istanbul, Turkey, 11-14 May 2016; Uddin, M.S., Sahin, M., Eds.; Özyeğin University: Istanbul, Turkey, 2016; pp. 519-525.

6. Sevaldson, B. Developing Digital Design Techniques: Investigations on Creative Design Computing, 1st ed.; Oslo School of Architecture and Design: Oslo, Norway, 2005.

7. Jones, P.; Kijima, K. (Eds.) Systemic Design; Springer: Tokyo, Japan, 2018; Volume 8. [CrossRef]

8. Harman, G. Tool-Being: Heidegger and the Metaphysics of Objects; Open Court: Lima, Peru, 2002.

9. Hensel, M.; Turko, J. Grounds and Envelopes: Reshaping Architecture and Built Environment; Routledge: Abingdon, UK, 2015. 
10. Steffen, W.; Richardson, K.; Rockström, J.; Cornell, S.E.; Fetzer, I.; Bennett, E.M.; Biggs, R.; Carpenter, S.R.; De Vries, W.; De Wit, C.A.; et al. Planetary boundaries: Guiding human development on a changing planet. Science 2015, 347, 1259855. [CrossRef] [PubMed]

11. Bratton, B.H. Some Trace Effects of the Post-Anthropocene: On Accelerationist Geopolitical Aesthetics. J. E-Flux 2013, 46, 1-12.

12. Jagodzinski, J. SK-Interfaces: Telematic and Transgenic Art's Post-Digital Turn to Materiality. In Activist Media and Biopolitics: Critical Media Interventions in the Age of Biopower; Sützl, W., Hug, T., Eds.; Innsbruck University Press: Innsbruck, Austria, 2012; pp. 81-99. [CrossRef]

13. Czech Republic Ministry of the Environment, Czech Hydrometeorological Institute. Strategie Přizpůsobení se Změně Klimatu v Podmínkách ČR/Strategy on Adaptation to Climate Change in the Czech Republic, 1st ed.; Czech Republic Ministry of the Environment: Prague, Czech Republic, 2015.

14. Flæte, O.; Bardalen, A.; Dalen, L.; Drange, H.; Gjærum, I.; Hanssen-Bauer, I.; Karlsen, J.; Ottesen, P.; Sundby, S.; Drange, H.; et al. Adapting to a Changing Climate: Norway's Vulnerability and the Need to Adapt to the Impacts of Climate Change. Available online: https:/ / www.regjeringen.no/contentassets/00f70698362f4f889cbe30c75bca4a48/pdfs/nou201020100010000en_pdfs.pdf (accessed on 9 October 2021).

15. Richardson, G.R.A. Adapting to Climate Change: An Introduction for Canadian Municipalities; Natural Resources Canada: Ottawa, ON, Canada, 2010.

16. U.S.Department of State. 2014 Climate Change Adaptation Plan; U.S. Department of State: Washington, DC, USA, 2014.

17. Department for Environment Food \& Rural Affairs (DEFRA). The National Adaptation Programme and the Third Strategy for Climate Adaptation Reporting; Department for Environment Food \& Rural Affairs (DEFRA): London, UK, 2018.

18. Wilson, E.O. Biodiversity research requires more boots on the ground: Comment. Nat. Ecol. Evol. 2017, 1, 1590-1591. [CrossRef] [PubMed]

19. Planke, T. The Role of the Craftsman in Cultural Heritage Protection. In Preserving the Stave Churches: Craftsmanship and Research; Bakken, K., Ed.; Pax Forlag: Oslo, Norway, 2016; pp. 1-32.

20. Saeidi, S. Envelopes and exteriority: Local specificity and extended exterior as design criteria for architectural envelopes. Form Akad. 2019, 12. [CrossRef]

21. Irwin, T. Transition design: A proposal for a new area of design practice, study, and research. Des. Cult. 2015, 7, 229-246. [CrossRef]

22. Morton, T. Poisoned Ground: Art and Philosophy in the Time of Hyperobjects. Symploke 2013, 21, 37-50. [CrossRef]

23. Thackara, J. Bioregioning: Pathways to Urban-Rural Reconnection. She Ji J. Des. Econ. Innov. 2019, 5, 15-28. [CrossRef]

24. Meadows, D. Leverage Points: Places to Intervene in a System; Hartland: Rock Falls, IL, USA, 1999.

25. Friedman, K. The Design Continuum-From Simplicity to Complex Systems. She Ji J. Des. Econ. Innov. 2016, 2, 103-104. [CrossRef]

26. Leatherbarrow, D. Architecture Oriented Otherwise; Princeton Architectural Press: New York, NY, USA, 2009.

27. Addington, M.; Schodek, D.L. Smart Materials and Technologies in Architecture, 1st ed.; Architectural Press: Oxford, UK, 2005.

28. Addington, M. Contingent Behaviours. Archit. Des. 2009, 79, 12-17. [CrossRef]

29. Hensel, M. Performance-Oriented Architecture: Rethinking Architectural Design and the Built Environment, 1st ed.; John Willey \& Sons Ltd.: West Sussex, UK, 2013.

30. Hawkes, D. The Environmental Imagination: Technics and Poetics of the Architectural Environment, 2nd ed.; Taylor \& Francis: London, UK, 2020. [CrossRef]

31. Porteous, C. The New Eco-Architecture: Alternatives from the Modern Movement; Spon Press: London, UK, 2002.

32. Costa, A.A.D.A. Arquitetura do sol. Soluções Climáticas Produzidas em Recife Nos Anos 50. Available online: https://vitruvius. com.br/revistas/read/arquitextos/13.147/4466 (accessed on 9 October 2021).

33. Camacho, D.O.J.; Sacht, H.M.; Vettorazzi, E. De los elementos perforados al cobogó: Histórico de uso en la arquitectura brasilera y consideraciones sobre su adaptación al clima. PARC Pesqui. Em Arquitetura E Construção 2018, 8, 205-2016. [CrossRef]

34. Vegas, F.; Mileto, C.; García Soriano, L.; García Sáez, S. Shading and cooling systems. In Versus: Heritage for Tomorrow: Vernacular Knowledge for Sustainable Architecture; Correia, M., Dipasquale, L., Mecca, S., Eds.; Firenze University Press: Firenze, Italy, 2014; pp. 245-254.

35. Fathy, H. Natural Energy and Vernacular Architecture: Principles and Examples with Reference to Hot Arid Climates; The University of Chicago Press: Chicago, IL, USA, 1986.

36. Hensel, M. Thoughts and experiments en route to intensely local architectures. Nord. J. Archit. Res. 2015, 27, 61-83.

37. Fakouch, T.; Bitar, K.; Fakoush, O.; Badr, Y.; Mokayed, D.; Rifai, G.; Villaverde, M. Traditional Syrian Architecture, 1st ed.; Ecole d'Avignon: Avignon, France, 2004.

38. Sunguroğlu Hensel, D. Ecological Prototypes: Initiating Design Innovation in Green Construction. Sustainability 2020, $12,5865$. [CrossRef]

39. Hensel, M.; Sunguroğlu Hensel, D. Architectural History from a Performance Perspective-The Latent Potential of Knowledge embedded in the Built Environment. In Heritage and Technology: Mind Knowledge Experience: Le Vie Dei Mercanti XIII International; La Scuola di Pitagora, Ed.; La Scuola di Pitagora: Naples, Italy, 2015; pp. 794-802. [CrossRef]

40. Ossola, A.; Niemelä, J. (Eds.) Urban Biodiversity: From Research To Practice; Routledge: Abingdon, UK, 2018.

41. McVicar, M. Gathering-In-Action: The Activation of a Civic Space. Archit. Cult. 2020, 1-16. [CrossRef]

42. Joachim, M.; Aiolova, M. (Eds.) Design with Life: Biotech Architecture and Resilient Cities; Actar: New York, NY, USA, 2019. 
43. Moxon, S. Drawing on nature: A vision of an urban residential street adapted for biodiversity in architectural drawings. City Territ. Archit. 2019, 6, 1-13. [CrossRef]

44. Herrero Delicado, G.; Thompson, R. Eco-Visionaries: Conversations on a Planet in a State of Emergency. R. Acad. Arts. 2019. Available online: https:/ / www.royalacademy.org.uk/exhibition/architecture-environment-eco-visionaries (accessed on 29 September 2021).

45. Lynn, G. Intricate Surface. MAK Museum Vienna. 2003. Available online: https://www.mak.at/en/greg_lynn_ (accessed on 29 September 2021).

46. Davidová, M.; Gasseloğlu, M.A. Poster: GIGA-mapping the Architectural Performance: Appreciation of New Coming Cultures. In Proceedings of the Relating Systems Thinking and Design 2017, Oslo, Norway, 18-20 October 2017; Sevaldson, B., Ed.; Systemic Design Research Network: Oslo, Norway, 2017; p. 1.

47. Beck, H.E.; Zimmermann, N.E.; McVicar, T.R.; Vergopolan, N.; Berg, A.; Wood, E.F. Present and future Köppen-Geiger climate classification maps at 1-km resolution. Sci. Data 2018, 5, 180214. [CrossRef] [PubMed]

48. Sevaldson, B. Visualizing Complex Design: The Evolution of Gigamaps. In System Design; Jones, P., Kijima, K., Eds.; Springer: Tokyo, Japan, 2018; pp. 243-269. [CrossRef]

49. Gunaratne, S.A.; Gunaratne, Y.-S. A new vision of reality for communication research: Call for a paradigm shift to systems view of life. J. Multicult. Discourses 2017, 12, 1-22. [CrossRef]

50. Davidová, M.; Zatloukal, J.; Zímová, K. Responsive Transformer: The Bio-Robotic Adaptive Architecture. In Proceedings of the IDCK-International Design Conference, Karachi, Pakistan, 20-22 February 2017; pp. 1-8.

51. Alexander, C. Notes on the Synthesis of Form, 1st ed.; Harvard University Press: Cambridge, UK, 1964.

52. Davidová, M.; Uygan, E. Living in Bio-Climatic Layers: An Investigation of Cappadocian Caves in Relation to Today's Design and Its Futures. Available online: https:/ / www.researchgate.net/publication/313759290_Living_in_Bio-Climatic_Layers_An_ Investigation_of_Cappadocian_Caves_in_Relation_to_Today\%27s_Design_and_Its_Futures (accessed on 9 October 2021).

53. Davidová, M.; Raková, D. Biodiversity and Climate Change Adaptation through Non-Discrete Architectural Spaces and Architectures: Systemic Approach to Traditions for Sustainable Futures. Form Akad. -Res. J. Des. Des. Educ. 2018, 11, 1-31. [CrossRef]

54. Semper, G. The Four Elements of Architecture and Other Writings; Cambridge University Press: Cambridge, UK, 2010.

55. Sevaldson, B. Systems Oriented Design: The emergence and development of a designerly approach to address complexity. In Proceedings of the DRS/ /CUMULUS 2013, Oslo, Norway, 14-17 May 2013; Reitan, J.B., Lloyd, P., Bohemia, E., Nielsen, L.M., Digranes, I., Lutnaes, E., Eds.; HIOA: Oslo, Norway, 2013; pp. 14-17, ISBN 978-82-93298-00-7.

56. Davidová, M. Systemic Approach to Architectural Performance: The Media Mix in the Creative Design Process. Form Akad. -Res. J. Des. Des. Educ. 2017, 10, 1-25. [CrossRef]

57. Sevaldson, B. Gigamaps: Their role as bridging artefacts and a new Sense Sharing Model. In Relating Systems Thinking and Design 4 Working Paper; Systemic Design Research Network: Banff, AB, Canada, 2015; pp. 1-11.

58. Davidová, M. Socio-Environmental Relations of Non-Discrete Spaces and Architectures: Systemic Approach to Performative Wood. In Proceedings of the Relating Systems Thinking and Design 2016 Symposium (RSD), Toronto, ON, Canada, 13-15 October 2016; Jones, P., Ed.; Systemic Design Research Network: Toronto, ON, Canada, 2016; pp. 1-17.

59. Sevaldson, B. Discussions \& Movements in Design Research: A systems approach to practice research in design. Form Akad. 2010, 3, 8-35. [CrossRef]

60. Hensel, M.; Menges, A. Morpho-Ecologies, 1st ed.; AA Publications: London, UK, 2006.

61. Davidová, M. Cocreative roles, agencies and relations in post-Anthropocene: The real life gigamaps and full-scale prototypes of SAAP. Strateg. Des. Res. J. 2020, 13, 185-212. [CrossRef]

62. Davidová, M. Synergy in the systemic approach to architectural performance: The integral multi- and cross-layered agencies in eco-systemic generative design processes of the post-anthropocene. Form Akad.-Res. J. Des. Des. Educ. 2020, 13, 1-30. [CrossRef]

63. Davidová, M.; Pánek, K.; Pánková, M. Spiralling slope as a real life co-design laboratory. In Proceedings of the Critical Practice in an Age of Complexity, Tucson, AZ, USA, 22-23 February 2018; pp. 120-131.

64. Davidová, M.; Zímová, K. COLreg: The Tokenised Cross-Species Multicentred Regenerative Region Co-Creation. Sustainability 2021, 13, 6638. [CrossRef]

65. Spotswood, E.N.; Beller, E.E.; Grossinger, R.; Grenier, J.L.; Heller, N.E.; Aronson, M.F.J. The Biological Deserts Fallacy: Cities in Their Landscapes Contribute More than We Think to Regional Biodiversity. Bioscience 2021, 71, 148-160. [CrossRef]

66. Gehl, J. Life Between Buildings: Using Public Space; Island Press: Washington, DC, USA, 2011.

67. Chen, I.-C.; Hill, J.K.; Ohlemüller, R.; Roy, D.B.; Thomas, C.D. Rapid Range Shifts of Species Associated with High Levels of Climate Warming. Science 2011, 333, 1024-1026. [CrossRef] [PubMed]

68. Kempe, D.R.C. Living Underground: A History of Cave and Cliff Dwelling, 1st ed.; Herbert Press: London, UK, 1988.

69. Kamath, L.G.; Daketi, S. Jaalis: A study on aesthetics and functional aspects in built environment. Int. J. Sci. Eng. Appl. Sci. 2016, 2, 98-104.

70. Nousala, S.; Morris, A.; Hall, W.; Hadgraft, R. Do I know where I am going and why? Connecting Social Knowledge for Governance and Urban Action. J. Syst. Cybern. Inform. 2011, 9, 65-76.

71. Davidová, M. Multicentred Systemic Design Pedagogy Through Real-Life Empathy Integral and Inclusive Practice-Based Education in the Research-by-Design Context. Akad.-Res. J. Des. Des. Educ. 2020, 13, 1-26. [CrossRef] 
72. Davidová, M.; Prokop, Š. TreeHugger: The Eco-Systemic Prototypical Urban Intervention. In Proceedings of the 6th eCAADe RIS 2018 Proceedings, Wellington, New Zealand, 15-18 April 2019; Kontovourkis, O., Ed.; University of Cyprus: Nicosia, Cyprus, 2018; pp. 75-85.

73. Larsen, K.E.; Marstein, N. Conservation of Historic Timber Structures: An Ecological Approach; Reed Educational and Professional Publishing Ltd.: Oxford, UK, 2000.

74. Mycoteam, A.S.; Austigard, M.S. Muggsopptest av Trevirke med Ulik Behandling. 2014.

75. Morin, E. Restricted complexity, general complexity. In Worldviews, Science, and Us: Philosophy and Complexity; Gershenson, C., Aerts, D., Edmonds, B., Eds.; World Scientific: London, UK, 2007; pp. 5-29. [CrossRef]

76. Smith-Nonini, S. Making Complexity Your Friend: Reframing Social Theory for the Anthropocene. Weather Clim. Soc. 2017, 9, 687-699. [CrossRef]

77. Davidová, M.; Zímová, K. COLridor: Co-Design and Co-Living Urban Adaptation. Akad. -Res. J. Des. Des. Educ. 2018, 11, 1-30. [CrossRef]

78. McIntyre-Mills, J. Systemic Ethics for Social and Environmental Justice. In Systemic Ethics and Non-Anthropocentric Stewardship; McIntyre-Mills, J., Ed.; Springer: Cham, Switzerland, 2014; pp. 121-153. [CrossRef]

79. Haase, A. The Contribution of Nature-Based Solutions to Socially Inclusive Urban Development-Some Reflections from a SocialEnvironmental Perspective; Springer: Cham, Switzerland, 2017; pp. 221-236. [CrossRef]

80. Capra, F. Fritjof Capra on Science and Spirituality. Available online: http://www.sutrajournal.com/science-and-spirituality-byfritjof-capra (accessed on 9 October 2021).

81. Morton, T. Dark Ecology: For a Logic of Future Coexistence; Columbia University Press: New York, NY, USA, 2016.

82. Latour, B. Reassembling The Social: An Introduction to Actor-Network-Theory; Oxford University Press: Oxford, UK, 2005.

83. Margulis, L.; Matthews, C.N.; Haselton, A. (Eds.) Environmental Evolution: Effects of the Origin and Evolution of Life on Planet Earth; MIT Press: Cambridge, MA, USA, 2000.

84. Kropp, C.; Da Ros, C. Alternative food politics: The production of urban food spaces in Leipzig (Germany) and Nantes (France). In Food System Transformations Social Movements, Local Economies, Collaborative Networks, 1st ed.; Kropp, C., Antoni-Komar, I., Sage, C., Eds.; Routledge: Abingdon, UK, 2021; pp. 42-68. [CrossRef]

85. Srivastav, S.; Jones, P.J. Use of traditional passive strategies to reduce the energy use and carbon emissions in modern dwellings. Int. J. Low-Carbon. Technol. 2009, 4, 141-149. [CrossRef]

86. Ehrenfeld, J. Flourishing: Designing a Brave New World. She Ji J. Des. Econ. Innov. 2019, 5, 105-116. [CrossRef]

87. Ehrenfeld, J.; Hoffman, A.J. Flourishing: A Frank Conversation About Sustainability, 1st ed.; Stanford University Press: Stanford, CA, USA, 2013.

88. Hensel, M. Auxiliary Architectures: Augmenting Existing Architectures with Performative Capacities. Archit. Des. 2015, 85, 116-119. [CrossRef]

89. Lovelock, J. Gaia: A New Look at Life on Earth; OUP Oxford: Oxford, UK, 2000.

90. Davidová, M. The Facade and Roofing System That is Ventilating in Dry Conditions and Enclosing in Humid Weather/Fasádní A Pleakrytinový Systém, Větrající Za Sucha A Uzavírající Se Za Vlhkého Počasí. CZ 307893 B6; 05.09.2013. 